\title{
Disparities in acute lymphoblastic leukemia risk and survival across the lifespan in the United States of America
}

\author{
Keren $\mathrm{Xu}^{1,2}$, Qianxi Feng ${ }^{1,2}$, Joseph L. Wiemels ${ }^{1,2}$, Adam J. de Smith ${ }^{1,2}$ \\ ${ }^{1}$ Center for Genetic Epidemiology, Department of Preventive Medicine, Keck School of Medicine of the University of Southern \\ California, Los Angeles, CA 90033, USA. \\ ${ }^{2}$ Norris Comprehensive Cancer Center, University of Southern California, Los Angeles, CA 90033, USA. \\ Correspondence to: Dr. Adam J. de Smith, Center for Genetic Epidemiology, Department of Preventive Medicine, Keck School of \\ Medicine of the University of Southern California, 1450 Biggy St., NRT-1509H, USC Norris Comprehensive Cancer Center, Los \\ Angeles, CA 90033, USA. E-mail: adam.desmith@med.usc.edu
}

\begin{abstract}
How to cite this article: Xu K, Feng Q, Wiemels JL, de Smith AJ. Disparities in acute lymphoblastic leukemia risk and survival across the lifespan in the United States of America. J Trans/ Genet Genom 2021;5:218-39.

https://dx.doi.org/10.20517/jtgg.2021.20
\end{abstract}

Received: 7 Apr 2021 Accepted: 3 Jun 2021 First online: 8 Jun 2021

Academic Editor: Susan L. Slager Copy Editor: Xi-Jun Chen Production Editor: Xi-Jun Chen

\begin{abstract}
Acute lymphoblastic leukemia (ALL) is the most common childhood cancer but is less frequent in adolescents and young adults (AYAs) and is rare among older adults. The 5-year survival of ALL is above $90 \%$ in children, but drops significantly in AYAs, and over half of ALL-related deaths occur in older adults. In addition to diagnosis age, the race/ethnicity of patients consistently shows association with ALL incidence and outcomes. Here, we review the racial/ethnic disparities in ALL incidence and outcomes, discuss how these vary across the age spectrum, and examine the potential causes of these disparities. In the United States, the incidence of ALL is highest in Hispanics/Latinos and lowest in Black individuals across all age groups. ALL incidence is rising fastest in Hispanics/Latinos, especially in AYAs. In addition, survival is worse in Hispanic/Latino or Black ALL patients compared to those who are non-Hispanic White. Different molecular subtypes of ALL show heterogeneities in incidence rates and survival outcomes across age groups and race/ethnicity. Several ALL risk variants are associated with genetic ancestry, and demonstrate different risk allele frequencies and/or effect sizes across populations. Moreover, non-genetic factors including socioeconomic status, access to care, and environmental exposures all likely influence the disparities in ALL risk and survival. Further studies are needed to investigate the potential joint effects and interactions of genetic and environmental risk factors. Improving survival in Hispanic/Latino and Black patients with ALL requires advances in precision medicine approaches, improved access
\end{abstract}

The Author(s) 2021. Open Access This article is licensed under a Creative Commons Attribution 4.0 International License (https://creativecommons.org/licenses/by/4.0/), which permits unrestricted use, sharing, adaptation, distribution and reproduction in any medium or format, for any purpose, even commercially, as long as you give appropriate credit to the original author(s) and the source, provide a link to the Creative Commons license, and indicate if changes were made. 
to care, and inclusion of more diverse populations in future clinical trials.

Keywords: Acute lymphoblastic leukemia, disparities, race/ethnicity, genetic variation, socioeconomic status, access to care, recruitment to clinical trials, children, adolescents and young adults

\section{INTRODUCTION}

Acute lymphoblastic leukemia (ALL) is a hematologic malignancy characterized by impaired differentiation, proliferation, and accumulation of B- and T-lineage lymphoid precursor cells in the bone marrow, peripheral blood, and other organs $s^{[1,2]}$. In the United States, the age-adjusted incidence rate (AAIR) for ALL was estimated to be 1.64 per 100,000 people ${ }^{[3]}$, with approximately 5700 new cases and 1600 deaths projected to occur in $2021^{[4]}$. The incidence rate (IR) of ALL demonstrates a bimodal age pattern, in which the initial peak occurs at age 1-4 years, followed by a decline at age 20-59 years and a modest rise at ages above 60 years $^{[5]}$. Indeed, ALL is the most common childhood malignancy, with approximately 2700 incident ALL cases diagnosed under age 15 each year in the United States ${ }^{[6]}$.

The causes of ALL are multifactorial, and likely vary based on the molecular subtype and patient age of diagnosis ${ }^{[7]}$. Only a small proportion $(<10 \%)$ of ALL cases are attributable to known risk factors with large effects $^{[8]}$, namely ionizing radiation and congenital syndromes ${ }^{[9-13]}$, although both common and rare genetic variants are now known to contribute to childhood ALL risk ${ }^{[14]}$. Genome-wide association studies (GWAS) of childhood ALL have identified multiple genomic regions harboring common risk alleles for ALL, including at: 7p12.2 (IKZF1), 8q24.21, 9p21.3 (CDKN2A/B), 10p12.2 (PIP4K2A), 10p12.31 (BMI1), 10p14 (GATA3), 10q21.2 (ARID5B), 10q26.13 (LHPP), 12q23.1 (ELK3), 14q11.2 (CEBPE), 16p13.3 (USP7), 17q12, and $21 \mathrm{q} 22.2(E R G)^{[15-32]}$ [Table 1]. In addition, sequencing studies of familial and sporadic ALL have discovered rare germline variants in $P A X 5^{[33,34]}, E T V 6^{[35-39]}, I K Z F 1^{[40-42]}$, and TP53 $3^{[33,44]}$ that are associated with disease risk. Non-genetic factors also contribute to ALL risk; for example, there is strong epidemiological evidence supporting a role for early life infections and modulation of the developing immune system in childhood ALL etiology, which has been reviewed in detail elsewhere ${ }^{[45]}$. Studies have also reported modest associations for childhood ALL risk with several environmental exposures ${ }^{[46]}$, including tobacco smoke ${ }^{[47-49]}$, pesticides $^{[50,51]}$, paint ${ }^{[52,53]}$, and air pollution ${ }^{[54-56]}$. The vast majority of epidemiologic studies for ALL have been conducted in children, and very little is known regarding potential differences in ALL etiology across age groups.

One factor that consistently shows association with ALL incidence is race/ethnicity. We acknowledge that race and ethnicity are dynamic and multifactorial concepts ${ }^{[60]}$, and in this review we use the term race/ethnicity to refer to heterogeneous groups of people defined by the USA Office of Management and Budget as African Americans/Blacks (hereafter, Blacks); Hispanics/Latinos; American Indians and Alaska Natives (AI/ANs); and Asians and Native Hawaiians/other Pacific Islanders (APIs) ${ }^{[61]}$. Race/ethnicity reflects genetic ancestry, and additionally conveys important epidemiologic information as to how social determinants such as racism and discrimination, socioeconomic position, and environmental exposures can influence disease incidence and mortality ${ }^{[60]}$. In the United States, the incidence of ALL is highest in Hispanics/Latinos and lowest in Blacks, and this is consistent across age groups ${ }^{[5,62-66]}$.

Race/ethnicity is also associated with ALL patient outcomes. Overall, survival of ALL patients has improved dramatically in recent decades ${ }^{[3]}$, primarily in children ${ }^{[2,67]}$, which can largely be attributed to improvements in combination chemotherapy protocols ${ }^{[2]}$, as well as advances in the understanding of cytogenetics and genetics of the disease and, more recently, the development of immunotherapy and targeted therapies ${ }^{[68-70]}$. 
Table 1. Genetic variants associated with ALL risk in genome-wide association studies

\begin{tabular}{|c|c|c|c|c|c|c|c|c|c|c|c|c|c|c|}
\hline Gene & Region & SNP & Ref & Alt & Risk & Trait(s) & PubMed ID & Year & First author & AF_afr & AF_amr & AF_nfe & $P$ & OR (CI) \\
\hline$A R I D 5 B$ & $10 \mathrm{q} 21.2$ & rs10821936 & C & $T$ & C & ALL & 19684603 & 2009 & Treviño LR & 0.227 & 0.463 & 0.302 & $1.40 \mathrm{E}-15$ & $1.91(1.60-2.20)$ \\
\hline ARID5B & $10 \mathrm{q} 21.2$ & rs10994982 & A & G & A & ALL & 19684603 & 2009 & Treviño LR & 0.565 & 0.560 & 0.467 & 5.70E-09 & $1.61(1.30-1.90)$ \\
\hline ARID5B & $10 \mathrm{q} 21.2$ & rs7089424 & T & G & G & ALL & 19684604 & 2009 & Papaemmanuil E & 0.241 & 0.460 & 0.304 & 7.00E-19 & $1.65(1.54-1.76)$ \\
\hline ARID5B & $10 \mathrm{q} 21.2$ & rs7089424 & $\mathrm{T}$ & G & G & B-ALL & 19684604 & 2009 & Papaemmanuil E & 0.241 & 0.460 & 0.304 & $1.41 \mathrm{E}-19$ & $1.70(1.58-1.81)$ \\
\hline BAK1 & $6 p 21.31$ & rs210143 & T & C & C & B-ALL (High-hyperdiploidy) & 31767839 & 2019 & Vijayakrishnan J & 0.735 & 0.718 & 0.724 & $2.21 \mathrm{E}-08$ & $1.30(1.19-1.43)$ \\
\hline BM/1 & 10p12.31 & rs4748793 & A & G & A & ALL & 23512250 & 2013 & XuH & 0.893 & 0.774 & 0.787 & 8.40E-09 & $1.40(1.26-1.57)$ \\
\hline BM/1 & 10p12.31 & rs11591377 & G & $A$ & G & ALL & 29923177 & 2018 & de Smith AJ & 0.905 & 0.767 & 0.793 & 2.07E-10 & $1.27(1.20-1.35)$ \\
\hline C5orf56 & $5 q 31.1$ & rs886285 & T & C & $T$ & B-ALL (High-hyperdiploidy) & 31767839 & 2019 & Vijayakrishnan J & 0.647 & 0.304 & 0.343 & $1.56 \mathrm{E}-08$ & $1.29(1.18-1.41)$ \\
\hline CCDC26 & $8 q 24.21$ & rs28665337 & c & $A, T$ & A & B-ALL & 29632299 & 2018 & Vijayakrishnan J & 0.086 & 0.097 & 0.116 & 4.00E-09 & $1.34(1.21-1.47)$ \\
\hline$C C D C 26$ & $8 q 24.21$ & rs4617118 & A & $C, G$ & G & ALL & 29348612 & 2018 & Wiemels JL & 0.305 & 0.117 & 0.163 & 3.05E-09 & $1.27(1.17-1.38)$ \\
\hline CDKN2A & $9 p 21.3$ & rs3731217 & A & $C, T$ & A & ALL & 20453839 & 2010 & Sherborne AL & 0.902 & 0.898 & 0.867 & $3.01 E-11$ & $1.41(1.28-1.56)$ \\
\hline CDKN2A & $9 p 21.3$ & rs3731249 & c & T & $T$ & ALL & 26527286 & 2015 & Walsh K & 0.004 & 0.016 & 0.033 & $1.69 \mathrm{E}-13$ & $2.97(2.22-3.96)$ \\
\hline CDKN2B & $9 p 21.3$ & rs77728904 & A & $C, G$ & C & B-ALL & 26868379 & 2016 & Hungate EA & 0.094 & 0.059 & 0.080 & $3.32 \mathrm{E}-15$ & $1.72(1.50-1.97)$ \\
\hline CEBPE & $14 q 11.2$ & rs2239633 & G & A & G & B-ALL (ETV6-RUNX1) & 22076464 & 2012 & Ellinghaus $\mathrm{E}$ & 0.787 & 0.599 & 0.519 & $4.00 \mathrm{E}-10$ & $1.35(1.22-1.47)$ \\
\hline CEBPE & $14 q 11.2$ & rs4982731 & c & $\mathrm{T}$ & C & ALL & 23512250 & 2013 & XuH & 0.396 & 0.368 & 0.278 & $9.00 \mathrm{E}-12$ & $1.36(1.24-1.48)$ \\
\hline CPSF2 & $14 q 32.12$ & rs189434316 & A & $\mathrm{T}$ & $\mathrm{T}$ & B-ALL (Normal cytogenetic) & 29296818 & 2017 & Clay-Gilmour Al & 0.011 & 0.027 & 0.066 & $6.00 \mathrm{E}-09$ & $3.70(2.50-6.20)$ \\
\hline ELK3 & $12 \mathrm{q} 23.1$ & rs4762284 & A & $\mathrm{T}$ & $\mathrm{T}$ & B-ALL & 27694927 & 2017 & Vijayakrishnan J & 0.449 & 0.480 & 0.299 & $8.00 \mathrm{E}-09$ & $1.19(1.12-1.26)$ \\
\hline$E R G$ & $21 q 22.2$ & rs2836365 & A & G & G & B-ALL & 30510082 & 2019 & Qian M & 0.197 & 0.360 & 0.329 & $3.76 \mathrm{E}-08$ & $1.56(1.33-1.83)$ \\
\hline$E R G$ & $21 q 22.2$ & rs8131436 & G & C & C & ALL & 31296947 & 2019 & de Smith AJ & 0.196 & 0.363 & 0.331 & $8.76 \mathrm{E}-09$ & $1.23(1.16-1.31)$ \\
\hline GATA3 & $10 p 14$ & rs3824662 & c & $A, T$ & A & B-ALL & 23996088 & 2013 & Migliorini G & 0.094 & 0.395 & 0.172 & $8.62 \mathrm{E}-12$ & $1.31(1.21-1.41)$ \\
\hline GATA3 & $10 p 14$ & rs3824662 & C & $A, T$ & $A$ & B-ALL (Ph-like) & 24141364 & 2013 & Perez-Andreu V & 0.094 & 0.395 & 0.172 & $2.17 \mathrm{E}-14$ & $3.85(2.71-5.47)$ \\
\hline |GF2BP1 & $17 q 21.32$ & rs10853104 & c & $G, T$ & $\mathrm{~T}$ & B-ALL (ETV6-RUNX1) & 31767839 & 2019 & Vijayakrishnan J & 0.663 & 0.420 & 0.508 & $1.82 \mathrm{E}-08$ & $1.33(1.21-1.47)$ \\
\hline IKZF1 & 7p12.2 & rs11978267 & A & G & G & ALL & 19684603 & 2009 & Treviño LR & 0.193 & 0.241 & 0.277 & $8.80 E-11$ & $1.69(1.40-1.90)$ \\
\hline IKZF1 & 7p12.2 & rs4132601 & T & G & G & ALL & 19684604 & 2009 & Papaemmanuil E & 0.193 & 0.242 & 0.275 & 1.00E-19 & $1.69(1.58-1.81)$ \\
\hline IKZF1 & $7 \mathrm{p} 12.2$ & rs4132601 & T & G & G & B-ALL & 19684604 & 2009 & Papaemmanuil E & 0.193 & 0.242 & 0.275 & $9.31 \mathrm{E}-20$ & $1.73(1.61-1.85)$ \\
\hline IKZF3 & $17 q 21.1$ & rs2290400 & T & C & $T$ & ALL & 29348612 & 2018 & Wiemels JL & 0.518 & 0.619 & 0.510 & 2.05E-08 & $1.18(1.11-1.25)$ \\
\hline LHPP & $10 q 26.13$ & rs35837782 & A & G & G & B-ALL & 27694927 & 2017 & Vijayakrishnan J & 0.654 & 0.504 & 0.631 & $1.00 \mathrm{E}-11$ & $1.21(1.15-1.28)$ \\
\hline OR8U8 & $11 \mathrm{q} 12.1$ & rs1945213 & c & $G, T$ & C & B-ALL (ETV6-RUNX1) & 22076464 & 2012 & Ellinghaus E & 0.218 & 0.184 & 0.285 & $3.89 \mathrm{E}-08$ & $1.28(1.14-1.45)$ \\
\hline PIP4K2A & $11 \mathrm{q} 12.1$ & rs10828317 & T & C & $\mathrm{T}$ & B-ALL & 23996088 & 2013 & Migliorini G & 0.908 & 0.835 & 0.698 & 2.30E-09 & $1.23(1.15-1.32)$ \\
\hline PIP4K2A & 10p12.2 & rs7088318 & c & A & A & ALL & 23512250 & 2013 & XuH & 0.400 & 0.751 & 0.616 & $1.13 E-11$ & $1.40(1.28-1.53)$ \\
\hline PIP4K2A & 10p12.2 & rs4748812 & G & A & A & ALL & 29923177 & 2018 & de Smith AJ & 0.360 & 0.742 & 0.626 & $1.30 \mathrm{E}-15$ & $1.31(1.25-1.38)$ \\
\hline RPL6P5 & $2 q 22.3$ & rs17481869 & C & $A$ & $A$ & B-ALL (ETV6-RUNX1) & 29632299 & 2018 & Vijayakrishnan J & 0.020 & 0.036 & 0.079 & $3.20 \mathrm{E}-08$ & $2.14(1.64-2.80)$ \\
\hline
\end{tabular}




\begin{tabular}{|c|c|c|c|c|c|c|c|c|c|c|c|c|c|c|}
\hline SP4 & $7 p 15.3$ & rs2390536 & G & A & A & ALL & 29348612 & 2018 & Wiemels JL & 0.083 & 0.184 & 0.368 & $3.59 \mathrm{E}-08$ & $1.20(1.13-1.29)$ \\
\hline TLE1 & $9 q 21.31$ & rs76925697 & A & $\mathrm{T}$ & A & B-ALL & 31767839 & 2019 & Vijayakrishnan J & 0.964 & 0.969 & 0.962 & $2.11 \mathrm{E}-08$ & $1.52(1.31-1.76)$ \\
\hline TP63 & $3 q 28$ & rs17505102 & G & C & C & B-ALL (ETV6-RUNX1) & 22076464 & 2012 & Ellinghaus $\mathrm{E}$ & 0.053 & 0.064 & 0.128 & $8.94 \mathrm{E}-09$ & $1.59(1.33-1.92)$ \\
\hline JSP7 & 16p13.2 & rs74010351 & A & $C, G$ & G & T-ALL & 30938820 & 2019 & Qian M & 0.178 & 0.060 & 0.060 & $4.51 \mathrm{E}-08$ & $1.44(1.27-1.65)$ \\
\hline
\end{tabular}

Risk allele frequencies for the 33 ALL-associated SNPs are global frequencies obtained from gnomAD v2.1.1. ${ }^{[57]}$. Ref, alt, AF_af, AF_amr, and AF_nfe were annotated through ANNOVAR ${ }^{[58]}$. AF_af, AF_amr, and AF_nfe were transformed to indicate the allele frequency of the risk alleles. Other information was extracted from the GWAS Catalog and was confirmed in each publication. Gene: Nearest gene; SNP: single nucleotide polymorphism; ref: reference allele; alt: alternative allele; risk: risk allele; AF: allele frequency; afr: African/African American; amr: American Admixed/Latino; nfe: Non-Finnish European; OR: odds ratio; Cl: 95\% confidence interval; ALL: acute lymphoblastic leukemia. Two SNPs, rs10821936 and rs10994982, were identified within the same region by the same study and are included in this table as the causal variant is unknown ${ }^{[59]}$.

Although in children the overall 5-year survival rate of ALL has risen above $90 \%{ }^{[7,72]}$, it remains inferior in later age groups, with $60 \%-85 \%$ in adolescents and young adults (AYAs, age range varies by studies, between $15-39$ years) ${ }^{[7-76]}$, and under $30 \%$ in older adults ${ }^{[77-82]}$. In addition, ALL patients who are Hispanic/Latino or Black show worse outcomes compared to those who are non-Hispanic White (NHW) ${ }^{[83-89]}$.

Here, we review the racial/ethnic disparities in ALL incidence and outcomes, and discuss how these vary across the different age groups of patients: children, AYAs, and older adults. We also examine the potential causes of these disparities, including genetic and non-genetic risk factors, and how epidemiologic studies across populations are essential to our understanding the causes of ALL.

\section{DISPARITIES IN ALL INCIDENCE ACROSS THE LIFESPAN}

ALL incidence initially peaks in the first decade of childhood, ranging from 1-4 years to $<9$ years in different studies ${ }^{[5,64-66]}$, declines at age $20-59$ years, and rises again modestly among older adults aged 60 or above, with the highest second peak among Hispanic/Latino adults ${ }^{[00]}$. The initial peak of ALL incidence occurs earlier for B-cell ALL (B-ALL) at 1-4 years compared to T-cell ALL (T-ALL) at 5-14 years, and with a less prominent peak in the latter ${ }^{[5]}$. ALL develops more often in males than females with an incidence rate ratio (IRR) of 1.29 overall ${ }^{[3]}$, and 2.20 and 1.20 for T-ALL and for B-ALL, respectively ${ }^{[5]}$.

\section{Incidence of ALL is highest in Hispanics/Latinos}

Hispanic/Latino children are more likely to be diagnosed with ALL compared to NHW, Black or Asian children in both genders and across all age groups ${ }^{[5]}$. The reported Hispanic/Latino-to-NHW IRR of childhood ALL ranges from 1.25 to 1.65 for all subtypes combined ${ }^{[5,62,64-66]}$, and appears to be more prominent for B-ALL (IRR $=1.64$ ), but close to unity for T-ALL $(\mathrm{IRR}=0.94)^{[5]}$. Moreover, the disparity in ALL IRs between Hispanic/Latino and NHW children increases with increased age from $<1$ year to 19 years ${ }^{[64]}$. This disparity in ALL risk corresponds to what has been observed geographically. For instance, Latin American countries, including Mexico and Costa Rica, have some of the highest incidences of childhood ALL in the world ${ }^{[0,92]}$. Meanwhile, the highest incidence of childhood ALL in the United States is found in the West United States Census Region, where a high proportion of residents are Hispanics/Latinos ${ }^{[65]}$. On the contrary, compared to NHWs, Black children have lower IRs of nearly all ALL subtypes in all age groups ${ }^{[5,62,64-66]}$, and API children also have lower IRs ${ }^{[93]}$. 
Among API regional groups, East Asians have a significantly higher IR of childhood ALL compared to Southeast Asians ( $I R R=1.59)$, and Oceanians have the highest $\mathrm{IR}^{[93]}$.

Among AYAs aged 15-39 years (age range defined by the National Cancer Institute), the overall ALL AAIR was 0.98 (95\%CI: 0.96-1.01) per 100,000 during 2000-2016, with the highest incidence being observed in Hispanics/Latinos [AAIR = 1.63 (95\%CI: 1.56-1.70)], followed by AI/ANs [AAIR = 1.16 (95\%CI: 0.86-1.52)], NHWs [AAIR $=0.79(95 \%$ CI: 0.76-0.83)], APIs [AAIR $=0.78(95 \%$ CI: 0.70, 0.86) , and Blacks [AAIR $=0.53$ $(95 \%$ CI: $0.47,0.59)]^{[66]}$ [Figure 1]. A similar trend has been found in B-ALL specifically, with the highest incidence seen in Hispanics/Latinos and the lowest in Blacks ${ }^{[94]}$.

Among older adults, ALL incidence again predominates among Hispanics/Latinos ${ }^{[5]}$. For those aged 40 or older, Hispanics/Latinos had the highest AAIR [AAIR = 1.76 (95\%CI: 1.67-1.86)], followed by AI/ANs [AAIR $=1.17$ (95\%CI: 0.87-1.54)], NHWs [AAIR = 0.97 (95\%CI: 0.94-1.00)], APIs [AAIR = 0.85 (95\%CI: 0.78-0.93)], and Blacks [AAIR $=0.77$ (95\%CI: 0.70-0.84) $]^{[66]}$ [Figure 1].

Furthermore, Philadelphia chromosome-like (Ph-like) ALL [patients with a similar gene expression pattern as those with $\mathrm{t}(9 ; 22), B C R-A B L 1$ translocations, i.e., $\mathrm{Ph}+$ ], a subtype of $\mathrm{B}$-ALL associated with poor outcomes ${ }^{[95]}$, is more common in AYAs $(19 \%-27 \%)$ and older adults $(20 \%)$ than in children $(10 \%)^{[96-99]}$. In addition, patients with Ph-like ALL or with its subtype carrying CRLF2 rearrangement (also associated with poor outcomes) ${ }^{[99]}$ are more likely to be Hispanics/Latinos compared to other races/ethnicities (68\% in Phlike ALL and 85\% in Ph-like ALL with CRLF2 rearrangement $)^{[99]}$.

Intriguingly, a higher percentage of residents born in a foreign country at the county level contributes to a higher incidence of ALL among both NHWs and Blacks, but was contradictorily associated with a lower incidence of ALL among Hispanics/Latinos ${ }^{[6]}$. For United States-based API children, ALL IRs were similar to rates seen in originating countries ${ }^{[93]}$. The inverse association between percent foreign-born and the incidence of ALL in Hispanics/Latinos represents an example of the "Hispanic paradox" ${ }^{100,101]}$, which refers to the observation that foreign-born Hispanics/Latinos have better health outcomes when compared to United States-born Hispanics/Latinos.

\section{Incidence of ALL is rising fastest in Hispanics/Latinos}

During 1992-2013, the incidence of ALL increased significantly by approximately $2 \%$ per year for Hispanic/Latino children diagnosed from age 10-14 years (APC $=2.09$ ), and by $3 \%$ for those 15-19 years of age $(\mathrm{APC}=2.67)$, while no significant increases were observed in NHW, Black, or Asian children in the same age groups ${ }^{[64]}$. In the United States Cancer Statistics database, the IR of ALL in both overall children and Hispanic children aged below 20 years increased significantly during 2001-2008, with the largest increase being observed in Hispanic/Latino children ( $\mathrm{APC}=2.5$ ), and which remained stable during 2008$2014^{[65]}$.

Despite of the relatively low AAIR of ALL compared to other age groups, AYA had the greatest increase of ALL AAIR during 2000-2016 [overall APC = 1.56 (95\%CI: 1.03-2.09)] ${ }^{[66]}$ [Figure 1]. Hispanics/Latinos had significant increase of AAIR across all age groups [APC $=1.18$ (95\%CI: 0.76-1.60)], with the greatest increase found in AYAs [APC $=2.02\left(95 \% \mathrm{CI}\right.$ : 1.17-2.88) ${ }^{[66]}$. Across all age groups, AYA is the only group in which AI/ANs had a significant increase of AAIR [APC $=9.79$ (95\%CI: 5.65-14.09) $]^{[66]}$. Given the small population size of AI/ANs, the substantial interregional differences of incidence rates and misclassification of AI/ANs in central registries that were observed in SEER data ${ }^{[102]}$, a note of caution should be offered in interpreting rates and trends for the AI/AN population. The AAIR of ALL also increased significantly 


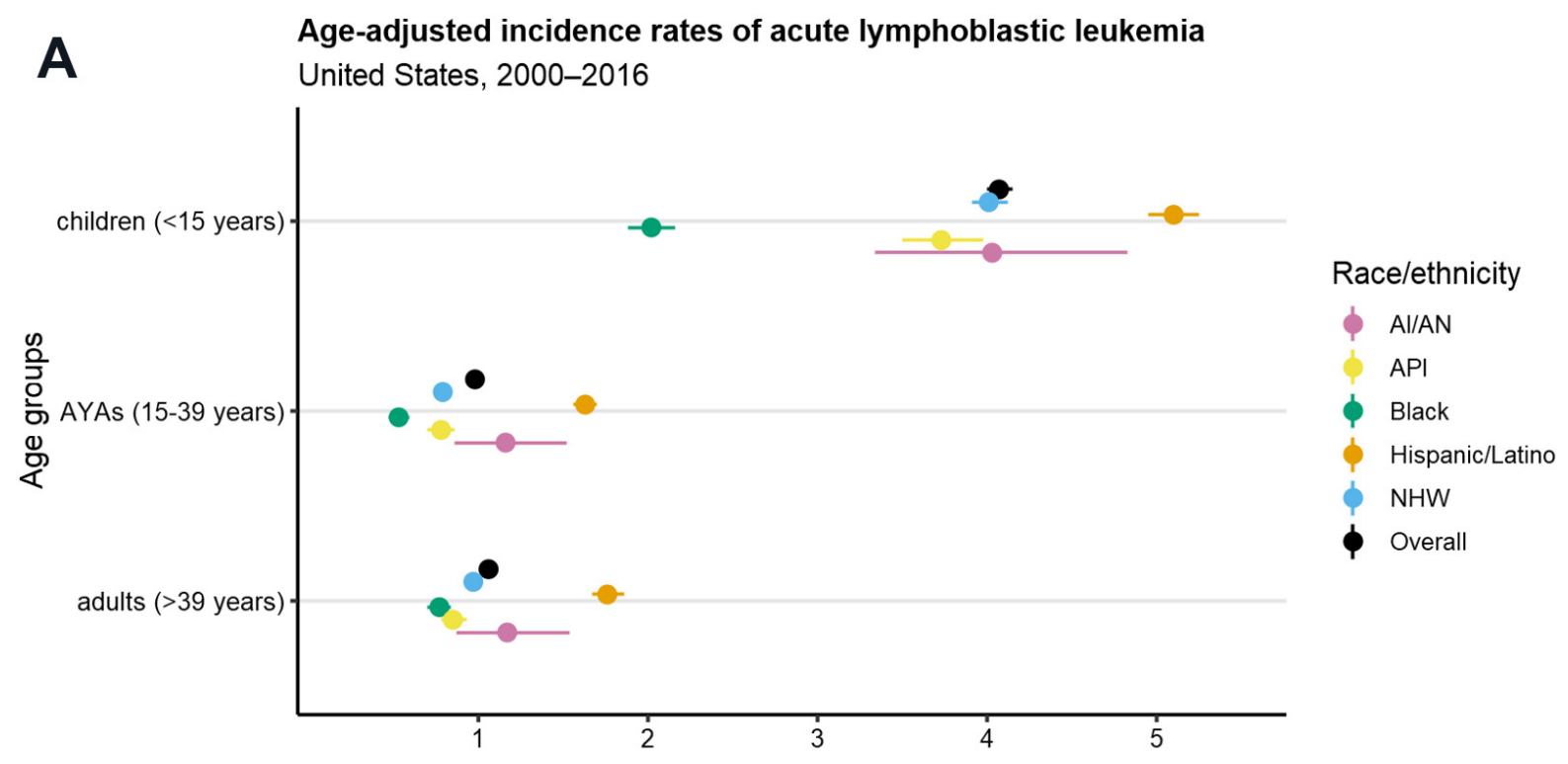

Age-adjusted incidence rates per 100,000 population

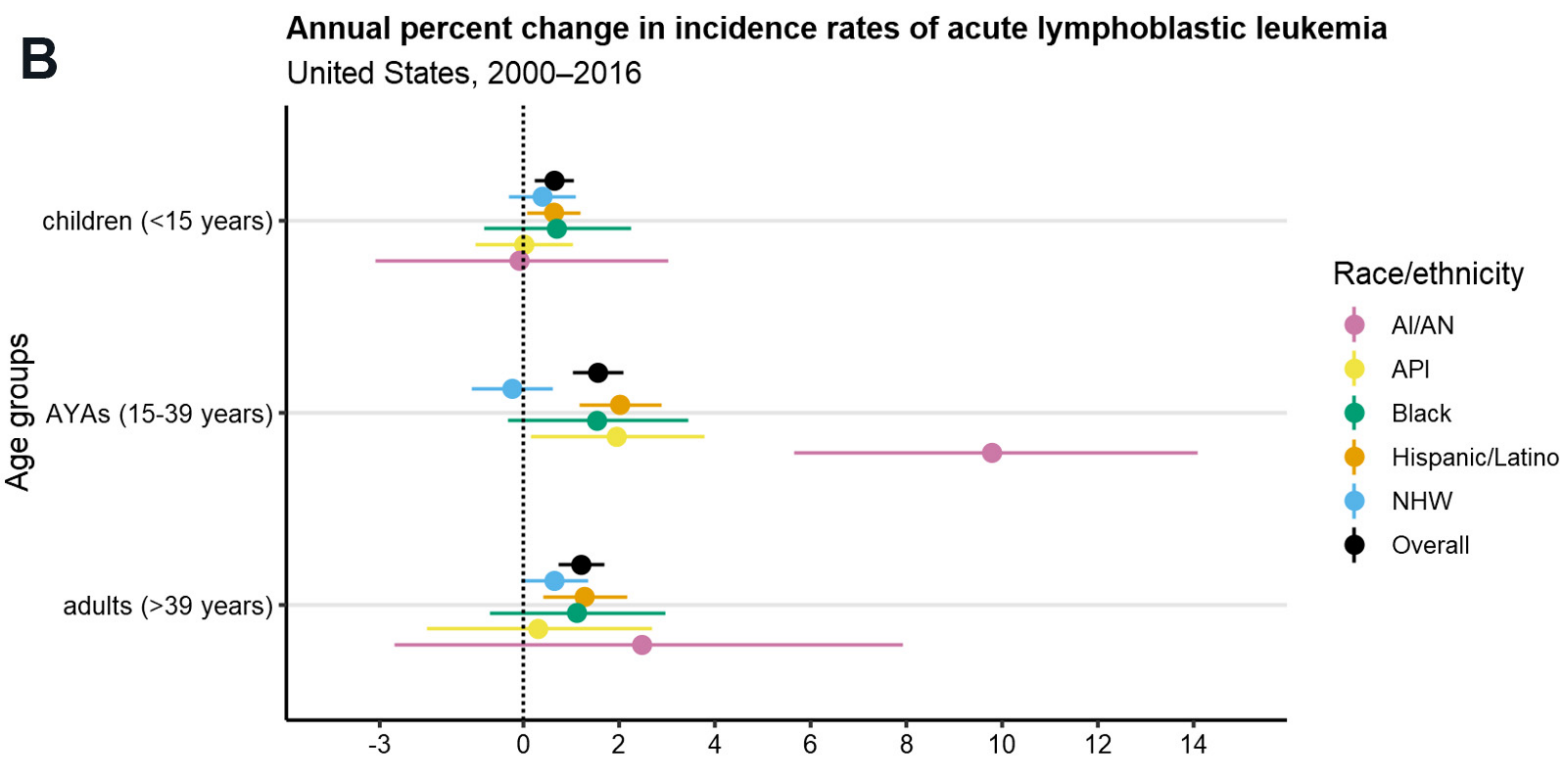

Annual percent change in incidence rates per 100,000 population

Figure 1. Disparities in acute lymphoblastic leukemia (ALL) incidence across the lifespan. Data extracted from Tables 1 and 2 from Feng et al. ${ }^{[66]}$. Age-adjusted incidence rate per 100,000 population was derived from the Surveillance, Epidemiology, and End Results Registry, version 18. Centers of points and horizontal bars indicate point estimates and $95 \%$ confidence intervals. (A) Age-adjusted incidence rates of ALL by age group and race/ethnicity, United States, 2000-2016. (B) Annual Percent Change in incidence rates of ALL by age group and race/ethnicity, United States, 2000-2016. Al/AN: American Indian and Alaska Native; API: Asian and Pacific Islander; Black: African American/Black; NHW: non-Hispanic White; AYAs: adolescents and young adults.

among API AYAs [APC = 1.95 (95\%CI: 0.15-3.79) $]^{[66]}$. Among older adults, the incidence of ALL increased significantly only among Hispanics/Latinos during 2000-2016 ${ }^{[66]}$. The trend of AAIR remained stable among NHWs and Blacks across all age groups over time ${ }^{[6]]}$. 


\section{DISPARITIES IN SURVIVAL OF ALL PATIENTS}

In this section, we summarize disparities in the overall survival rates of ALL patients, though we do not review potential disparities in long-term outcomes, such as treatment-related morbidities, which have been described elsewhere ${ }^{[103-106]}$.

\section{Children}

Among children, the survival of ALL is lowest in infants ( $<1$ year), highest in those aged 1-9 years, and thereafter, decreases with increased age ${ }^{[5,83]}$. Girls have better survival than boys overall ${ }^{[83]}$. Hispanic/Latino children have inferior outcomes compared to $\mathrm{NHWs}^{[83-87]}$, with a 5\%-15\% difference in overall survival rate being persistently seen in SEER data ${ }^{[84,85,87]}$. Furthermore, in Hispanics/Latinos, childhood ALL mortality has been shown to differ by genetic ancestry ${ }^{[107]}$. For instance, Hispanic/Latino children in general have a 2.27 times higher mortality compared to NHW children [mortality rate ratio $(\mathrm{MRR})=2.27(95 \% \mathrm{CI}: 1.68-3.06)$ ], with a MRR of 2.56 (95\%CI: 1.93-3.40) in continental Hispanic/Latino children (Mexicans, Central Americans, and South Americans) but with a MRR of only 1.23 (95\%CI: 0.74-2.03) in Caribbean Hispanic/Latino children (Puerto Ricans, Cubans, and Dominicans) ${ }^{[107]}$, suggesting that higher Indigenous American ancestry is associated with poorer overall survival.

In Black childhood ALL patients, improvement of 5 -year survival lags behind compared to in other races/ethnicities ${ }^{[108]}$. The largest improvements of survival in Blacks occurred at much later diagnosis periods (1995-2001 and 2002-2008) compared to those in NHWs and AI/ANs (1988-1994 and 19952001 ${ }^{[84]}$. Promisingly, SEER data have revealed a decreased inequality in ALL survival between Black and NHW children ${ }^{[83,85,109]}$. From 1992-1995 to 2003-2007, 5-year relative survival rate improved faster in Black children $(\mathrm{APC}=3.01)$ than in NHW children $(\mathrm{APC}=1.37)^{[85]}$. In another study, from 1975-1983 to 20002010, the difference in 5-year cumulative mortality of ALL between Black and NHW children reduced from $15 \%$ to $3 \%$; compared with NHWs, the adjusted hazard ratio (HR) for Blacks dropped from 1.46 (95\% CI: 1.09-1.94) to an insignificant 1.21 (95\%CI: $0.74-1.96)^{[83]}$.

API and AI/ANs also have significantly worse survival of childhood ALL compared to NHWs ${ }^{[8,84]}$, with the 5-year cumulative ALL mortality being $10 \%$ in APIs, and 19\% in AI/ANs versus being $8 \%$ in NHWs at 2000$2010^{[83]}$. Compared with NHW counterparts, APIs diagnosed at 1-9 years, and AI/ANs diagnosed at 10-19 years had about twice the ALL mortality $\mathrm{HR}^{[83]}$. Further, in a stratified analysis for Asian subgroups, when comparing to NHWs, East Asians in general (i.e., Chinese, Filipino, Korean, Japanese, Vietnamese and other Southeast Asians combined) had significant inferior outcomes, with particularly worse survival for Vietnamese [relative risk $(\mathrm{RR})=2.44(95 \% \mathrm{CI}: 1.50-3.97)]$ and Filipino $[\mathrm{RR}=1.64(95 \% \mathrm{CI}: 1.13-2.38)$ ] patients, whereas the inferior outcomes for Koreans, Japanese and other Southeast Asians were nonsignificant ${ }^{[84]}$.

\section{AYAs}

A "survival cliff" has been observed for ALL in AYA patients at age 17 to 20 years, where the survival rate drops considerably during just this 3-year difference in age, and accounts for nearly half of the total survival decrease from childhood to older adults ${ }^{[110]}$. This substantial drop of survival rate partly results from the high frequency of the high-risk Ph-like B-ALL subtype among AYAs ${ }^{[95-99]}$. Based on data obtained from the Texas Cancer Registry, among AYA ALL patients, the overall 5-year survival rate was better in females than in males, and it has improved over time across all races/ethnicities in both sex groups ${ }^{[88]}$. However, improvement in the survival rate of Black AYA patients lags behind other racial/ethnic groups, similar to the pattern seen in Black children. Among AYA patients, survival in Black males diagnosed in 2004-2012 [66.9\% (95\%CI: 64.0\%-69.6\%)] was significantly worse than in NHW [78.2\% (95\%CI: 77.2\%-79.1\%)] and in 
Hispanic/Latino males [71.8\% (95\%CI: 70.3\%-73.3\%)] diagnosed back in 1995-2003 ${ }^{[88]}$; Black females diagnosed in 2004-2012 [76.9\% (95\%CI: 75.2\%-78.4\%)] had a worse survival rate compared to NHW females diagnosed in 1995-2003 [83.9\% (95\%CI: $83.2 \%-84.2 \%)]^{[88]}$.

\section{Older adults}

Older adult ALL patients have the worst survival across all age group ${ }^{[77-82]}$. While approximately $22.5 \%$ of patients are diagnosed after the age of 55 years, $54.6 \%$ of ALL-related deaths occur in patients in this age stratum $^{[111]}$. This is likely related to the elevated prevalence of multiple high-risk subtypes of ALL in older adults. First, both Ph+ ALL and Ph-like ALL are very common subtypes of B-ALL among older adults aged 60 years or above (Ph+ ALL: approximately 50\%; Ph-like ALL: $24 \%-26 \%)^{[96-99,112,113]}$. In addition, older adults with $\mathrm{Ph}$-negative B-ALL tend to present with high-risk cytogenetics and complex karyotypes ${ }^{[114,115]}$ associated with increased risks of treatment failure and treatment complications ${ }^{[81]}$.

Promisingly, the 1973-2008 SEER data revealed a significant improvement for patients aged over 45 years in survival among the overall population, NHWs, and in particular APIs (19.8\%), and a large but marginally significant improvement for Blacks $(11.3 \%)^{[89]}$. However, these improvements were not seen in Hispanic/Latino patients. For instance, in 2003 to 2008, the 5-year survival rate of older adult Hispanic/Latino ALL patients was only $13.9 \%$ compared with $23.6 \%$ in NHWs and $17.1 \%$ in Blacks ${ }^{[89]}$, perhaps due to the high frequency of Ph-like ALL in Hispanic/Latino ALL patients ${ }^{[99]}$. Similarly, in the 19802011 SEER data, there was a modest improvement of median overall survival rate of ALL among adults aged 60 years or above $\mathrm{e}^{[116]}$, partly attributable to advances in novel therapies for $\mathrm{Ph}+\mathrm{ALL}^{[117]}$.

\section{FACTORS ASSOCIATED WITH DISPARITIES IN ALL RISK AND OUTCOMES Differences in ALL tumor biology}

Immunophenotype

The World Health Organization (WHO) classifies ALL based first on immunophenotype, and categorizes patients into either B-ALL or T-ALL ${ }^{[118]}$, with both comprising multiple subtypes defined by structural chromosomal alterations $^{[119]}$. B-ALL prevalence is higher than T-ALL, accounting for approximately $80 \%$ of ALL cases in children and $75 \%$ in adults in the United States ${ }^{[120]}$. In childhood ALL, the B-cell immunophenotype confers more favorable survival than T-ALL, whereas in adults survival is substantially higher for T-ALL than B-ALL ${ }^{[5,11,121,122]}$, likely due to differences in molecular subtypes across age groups. In both children and adults, B-ALL appears to have a higher incidence in Hispanics/Latinos compared to other races/ethnicities ${ }^{[5]}$. On the other hand, T-ALL occurs more frequently in Black children, in whom a T-ALLrelated genetic variant in USP7 is overrepresented ${ }^{[30]}$. Thus, the contribution of immunophenotype to disparities in the survival of ALL patients may vary across population groups.

\section{Cytogenetic subtypes}

The most common chromosomal alterations in childhood B-ALL are high hyperdiploidy (chromosomal number 51-67) and $\mathrm{t}(12 ; 21)(\mathrm{p} 13 ; \mathrm{q} 22)$ translocation encoding the ETV6-RUNX1 fusion gene ${ }^{[115,123]}$. Each presents in $25 \%-30 \%$ of children with ALL $^{[119]}$, and is associated with a favorable prognosis ${ }^{[115,124]}$. However, both subtypes are less common in adolescent ALL patients and very rare in adult ALL patients ${ }^{[119]}$. Among ALL cases in the California Childhood Leukemia Study, the prevalence of high hyperdiploidy was similar in Hispanics/Latinos and NHWs, at $28.3 \%$ and $27.6 \%$, respectively ${ }^{[25]}$, whereas there was a significantly lower frequency of ETV6-RUNX1 translocation in Hispanics/Latinos (13\%) than in NHWs $(24 \%)^{[126]}$. To our knowledge, the frequencies of these two subtypes have not been compared across race/ethnicity in AYAs or older adults, perhaps due to small numbers. 
The $\mathrm{Ph}$ chromosome translocation [ $\mathrm{t}(9 ; 22)$, i.e., $\mathrm{Ph}+]$, which results in the $B C R-A B L 1$ fusion gene ${ }^{[127]}$, is infrequent among childhood B-ALL patients $(<5 \%)$ but presents in up to half of adult B-ALL cases and becomes more prevalent with increased age ( $22 \%$ in patients $<40$ years of age, $41 \%$ in patients $\geq 40$ years and nearly $50 \%$ in patients aged 60 years or older $)^{[97,112,113]}$. A higher percent of $\mathrm{Ph}+\mathrm{B}$-ALL has been reported in Black AYA/adult patients compared with in NHW and Hispanic/Latino patients ${ }^{[99,128]}$. A similar pattern has been identified in children - compared with Ph-negative ALL patients, Ph+ ALL patients were more likely to be Black ${ }^{[29]}$. Although $\mathrm{Ph}$ chromosome has been historically recognized as an adverse prognostic factor for ALL, Ph+ ALL now has noninferior or even superior outcomes compared to Ph-negative ALL in older adult ALL patients ${ }^{[113,130,131]}$, due to recent advances in novel therapies such as CAR-T cell therapy and tyrosine kinase inhibitor therapy ${ }^{[117]}$.

The WHO 2017 revision introduced Ph-like ALL as an additional subgroup for B-ALL ${ }^{[118]}$. Ph-like B-ALL shares a similar gene-expression profile with $\mathrm{Ph}+\mathrm{B}-\mathrm{ALL}$, but does not harbor the $B C R-A B L 1$ fusion protein expressed from the $t(9 ; 22)^{[118]}$. Unlike Ph+ ALL that occurs more frequently with increased age, Ph-like ALL has the highest incidence in AYAs (19\%-28\%), a lower frequency in childhood (10\%), and is relatively common among adults aged 40 or above $(20 \%)^{[96-99]}$. Ph-like ALL partly contributes to the AYA "survival cliff' $^{[110]}$, and the continuing poor outcomes in older age groups ${ }^{[77-82]}$. Patients with Ph-like ALL had a significantly inferior event-free and disease-free survival, a lower complete remission rate, and an elevated level of minimal residual disease at the end of the induction therapy compared to non-Ph-like patients ${ }^{[95]}$. Furthermore, Ph-like ALL likely plays a role in both the high incidence and the inferior survival of ALL in Hispanics/Latinos. Ph-like ALL occurs more frequently in Hispanics/Latinos in particular in AYA/adults ${ }^{[99]}$. Indeed, Hispanics/Latinos have been shown to account for up to two-thirds of Ph-like ALL in AYA/adult patients ${ }^{[99]}$. Notably, nearly half of the patients with Ph-like ALL had CRLF2 rearrangements ${ }^{[96]}$. Both Ph-like ALL and its subtype with CRLF2 rearrangements have significantly worse outcomes compared to other subtypes ${ }^{[96,98,99,132-134]}$, and are more prevalent among Hispanics/Latinos compared to other racial/ethnic groups $^{[132]}$. In sum, the Ph-like subtype contributes significantly to the poor survival of Hispanic/Latino AYA ALL patients.

\section{Genetic variation}

Genetic variants contribute to racial/ethnic disparities in ALL incidence

Several ALL risk loci identified by GWAS have been associated with genetic ancestry, and have demonstrated differences in risk allele frequency and/or differences in effect size across population groups $^{[15-32,135,136]}$ [Figure 2]. For example, an increased number of risk alleles at 5 ALL risk single nucleotide polymorphisms (SNPs) rs3731217 (CDKN2A), rs7088318 (PIP4K2A), rs2239633 (CEBPE), rs7089424 (ARID5B), and rs3824662 (GATA3) was correlated with increased genome-wide Indigenous American ancestry in Hispanic/Latino children ${ }^{[137,138]}$. ARID $5 B$ SNP risk allele frequency has also been associated with increased local Indigenous American ancestry in Hispanics/Latinos ${ }^{[139]}$. At the GATA3 risk locus, SNP rs3824662 has a markedly higher risk allele frequency in Hispanic/Latino than in European ancestry populations, with $39 \%$ compared with only $17 \%$ frequency in the Genome Aggregation Database (gnomAD) v2.1.1. [Table 1 and Figure 3] ${ }^{[57]}$. Further, the GATA3 SNP rs3824662 risk allele has been shown to confer a remarkably high risk for Ph-like ALL in both children and AYAs, with an almost 4-fold risk of this subtype ${ }^{[2,135]}$, supporting that this risk locus likely contributes significantly to the increased prevalence of Ph-like ALL in Hispanic/Latino ALL patients.

In two recent GWAS of ALL conducted in Hispanic/Latino-only discovery studies, a novel ALL risk locus was identified at the chromosome 21 gene $E R G^{[2,313]}$. The effect of this locus on ALL risk was larger in Hispanics/Latinos than in NHWs and, in addition, this locus was associated with an increased risk of ALL in Hispanic/Latino individuals both with higher genome-wide and higher local Indigenous American 
A

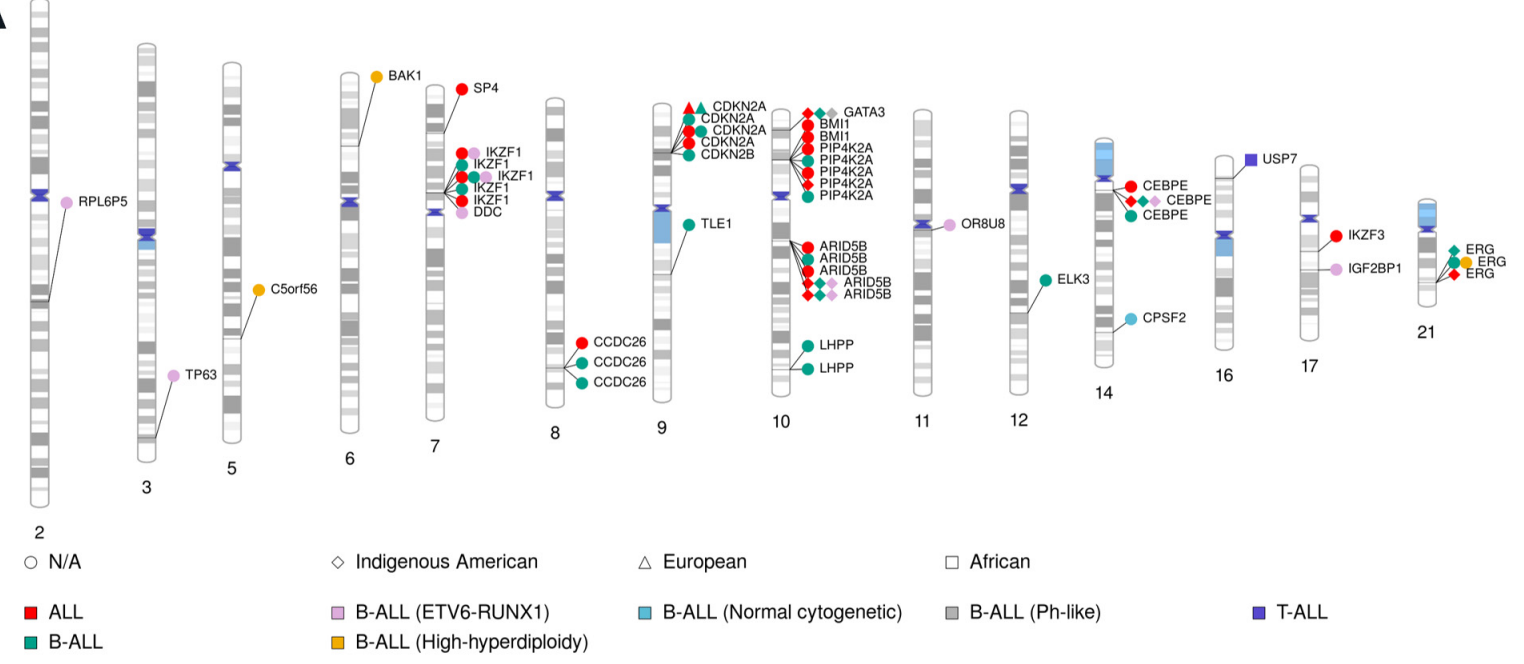

B

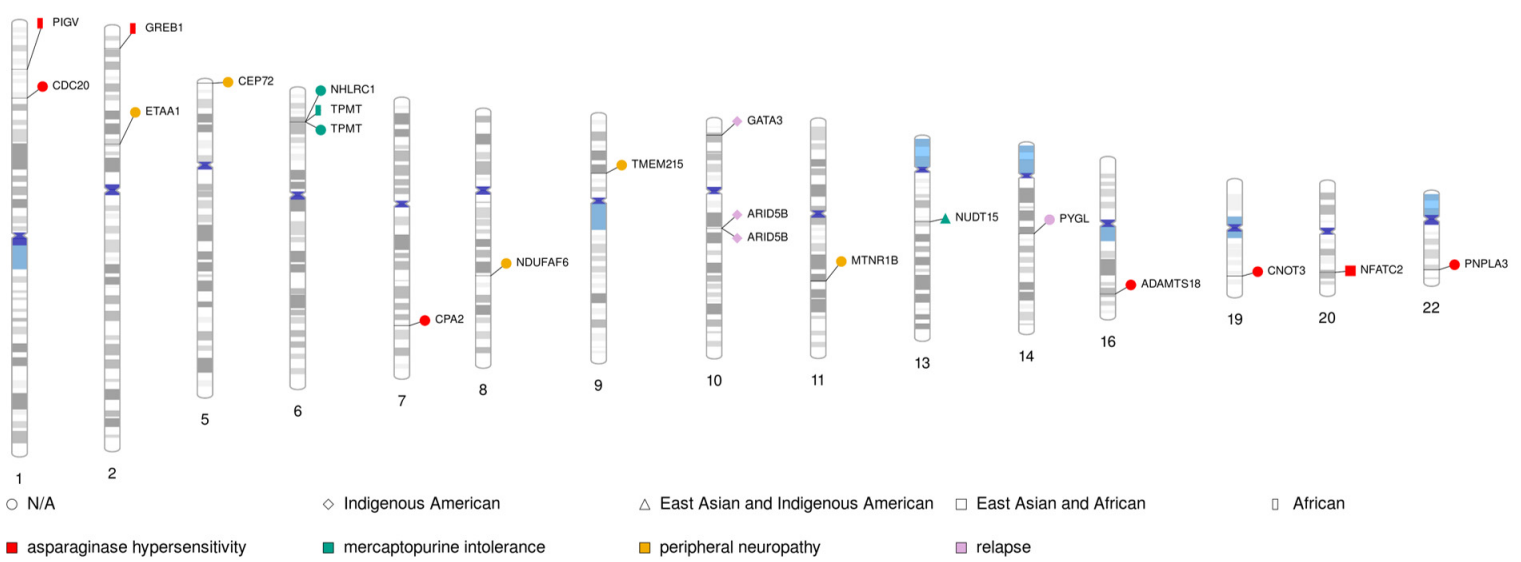

Figure 2. Genetic variants associated with ALL risk and outcomes across the genome. PhenoGram plots ${ }^{[140]}$ were constructed for genetic variants associated with (A) ALL susceptibility, and/or (B) ALL patient outcomes (i.e., relapse and response to therapy). Genetic variants included in the PhenoGrams were identified in the NHGRI-EBI catalog of human genome-wide association studies (GWAS Catalog) ${ }^{[141]}$ and included in published GWAS for acute lymphoblastic leukemia (ALL) ${ }^{[15,16,18-20,24-27,32,135,136]}$ or for outcomes of $\mathrm{ALL}^{[142-150]}$. We also included some variants described in additional papers included in this review for ALL susceptibility ${ }^{[17,21-23,28-31]}$ and ALL patient outcomes ${ }^{[21,139]}$. For ALL susceptibility $(A)$ we only included variants that passed genome-wide significance levels of $P<5 \times$ $10^{-8}$. For patient outcomes (B), we included variants that passed genome-wide significance levels of $P<5 \times 10^{-8}$ plus variants in GATA3 and ARID5B from gene-specific analyses. Lines are plotted on each chromosome corresponding to the base-pair position of each single nucleotide polymorphism (SNP). Variants are colored by related phenotypes that have been detected in GWAS (from the "Reported trait" column in the GWAS Catalog). Shapes of variants correspond to the genetic ancestry (if any) that has been associated with the SNP risk allele. N/A represents no related ancestry has been reported so far.

ancestry ${ }^{[2,33]}$. Together, risk loci in ARID5B, GATA3, PIP4K2A, CEBPE, and ERG likely account for some of the observed differences in ALL incidence between Hispanics/Latinos and non-Hispanic/Latino races/ethnicities, which may be partly explained by the Indigenous American ancestry in Hispanics/Latinos. Indeed, it has been suggested that the CEBPE, ARID5B, and GATA3 risk SNPs may account for approximately $3 \%, 11 \%$, and $11 \%$ increased risk of B-ALL in Hispanics/Latinos vs. NHWs, respectively ${ }^{[137,138]}$. Intriguingly, a recent study found that Indigenous American ancestry increased by $\sim 20 \%$ on average in Mexican Americans in the United States during the 1940s-1990s, partly attributable to assortative mating, shifts in migration pattern and changes in population size ${ }^{[151]}$. Given the association between ALL risk alleles and Indigenous American ancestry, this perhaps suggests that this shift in genetic ancestry may contribute to the rising ALL incidence among Hispanics/Latinos, although this warrants 
A Risk allele frequency percentage higher

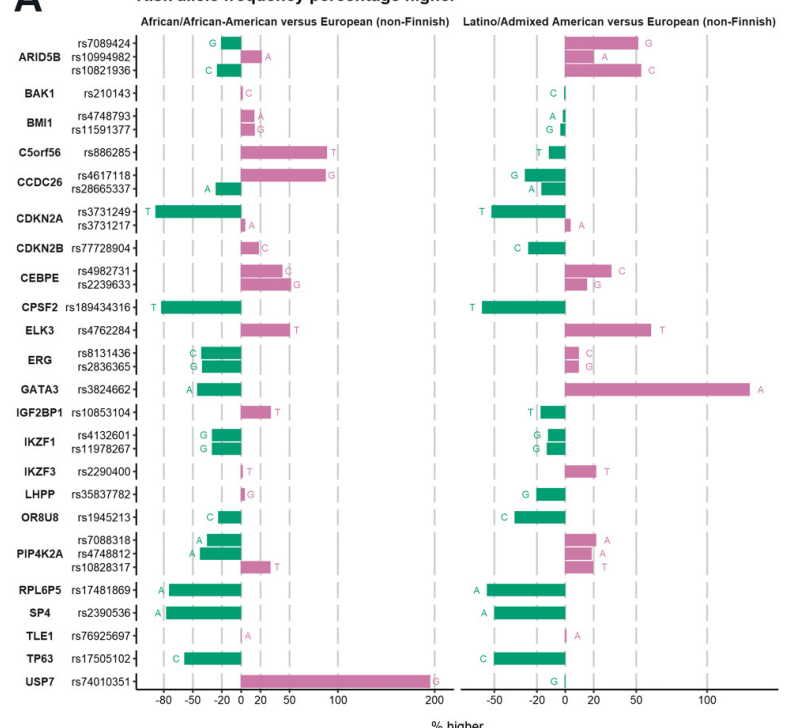

B Risk allele frequency absolute difference

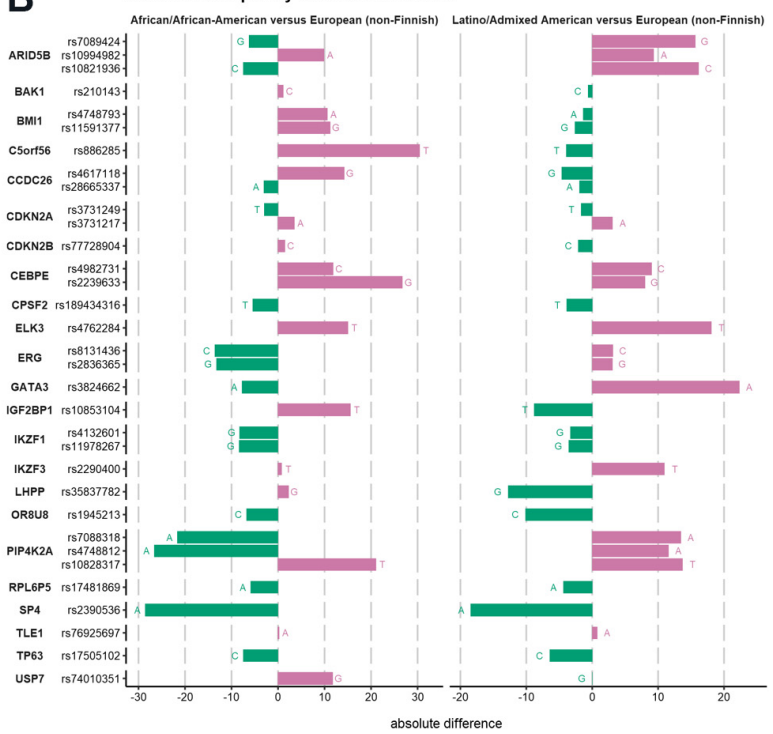

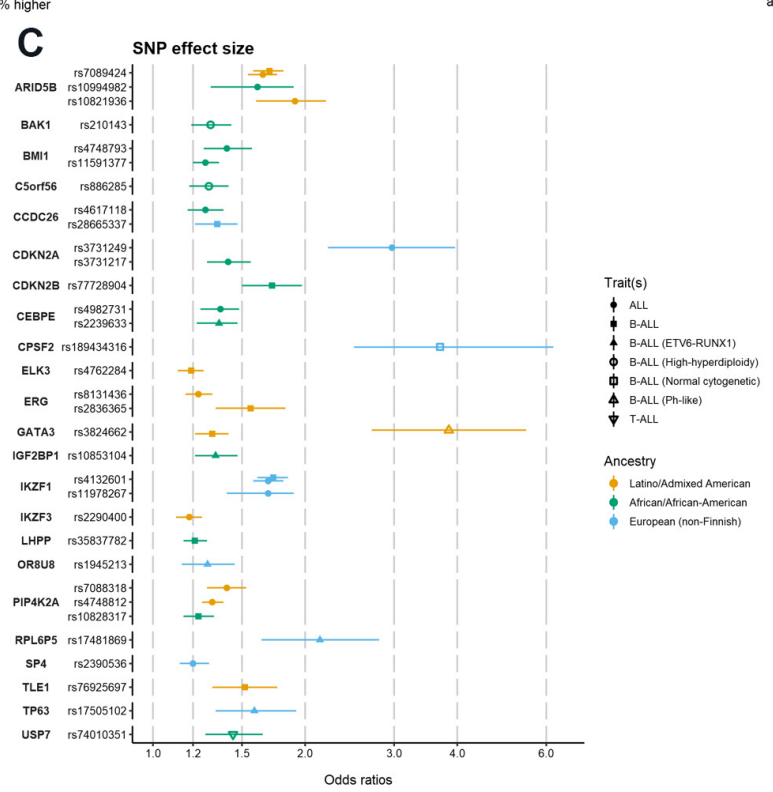

Figure 3. Risk allele frequency and effect size of selected single nucleotide polymorphisms (SNPs) associated with acute lymphoblastic leukemia (ALL) risk. SNPs ( $n=33$, Table 1) are grouped by nearest genes in each panel. (A) Percentage higher of risk allele frequency in Africans/African-Americans and Latinos/Admixed Americans as compared to in Europeans (non-Finnish). Percentage change equation: $\{\{[$ (Risk allele frequency of Africans/African-Americans or of Latinos/Admixed Americans) / [Risk allele frequency of Europeans (non-Finnish)]\} -1$\} \times 100$. Horizontal bars are annotated by risk allele and colored by the direction of percentage difference. (B) Difference of risk allele frequency in Africans/African-Americans and Latinos/Admixed Americans as compared to in Europeans (non-Finnish). (C) Effect size of selected GWAS-identified SNPs associated with ALL risk. Centers of points and horizontal bars indicate point estimates and $95 \%$ confidence intervals. Points are shaped by study-reported traits. Points and horizontal bars are colored by ancestry with the highest risk allele frequency. $X$ axis is on a log-10 scale in order to better present those relatively small effect sizes.

further investigation. Further research is needed to determine whether the ancestry-dependent effects from these SNPs are confounded by other genetic or environmental factors, and to discover additional ancestryassociated risk loci via admixture mapping and larger GWAS of ALL with a more diverse population across all age groups. 
Apart from the risk loci described above that are associated with Indigenous American ancestry, a novel risk locus for T-ALL was recently identified at the USP7 gene and was found to be overrepresented in children of African ancestry. This locus may, therefore, contribute to the higher incidence of T-ALL in Black children compared to their counterparts of other races/ethnicities ${ }^{[30]}$.

Finally, we summarized established GWAS-identified SNPs for ALL ${ }^{[15-32]}$ in Table 1, and we observed disparities in risk allele frequency and in effect size of these SNPs. In gnomAD (v2.1.1. ${ }^{[57]}$, the risk allele frequency of the Ph-like ALL-related SNP rs3824662 (GATA3) is 130\% higher in Latinos/Admixed Americans compared to in Europeans; further, SNPs in ARID5B have a $20 \%-50 \%$ higher risk allele frequency in Latinos/Admixed Americans compared to Europeans [Figure 3A]. Many of the established ALL GWAS SNPs have a higher absolute risk allele frequency in Latinos/Admixed Americans than in Europeans [Figure 3B]. In Blacks, risk allele frequency of the T-ALL-related SNP at rs74010351 (USP7) is strikingly high, nearly $200 \%$ higher than in Europeans, but the absolute difference is only $\sim 10 \%$ because of the low frequency of this risk allele across all populations [Table 1]; other GWAS SNPs did not show consistent differences in risk allele frequency between African and European populations [Figure 3]. The strongest risk effect is seen for the GATA3 SNP rs3824662 association with Ph-like ALL, with an effect size of nearly 4.0 [Figure $3 \mathrm{C}]$.

\section{Genetic variants are associated with racial/ethnic disparities in ALL outcomes}

Genetic variation contributes to racial/ethnic disparities not only in ALL susceptibility but also in treatment outcomes $^{[139,152]}$ [Figure 2]. Indigenous American ancestry has been associated with an increased risk of relapse in Hispanic/Latino ALL patients, which may result from the effects of ancestry-related genetic variants on therapy respons $\mathrm{e}^{[153]}$. For example, in a study conducted in children treated on Children's Oncology Group (COG) clinical trials, ARID5B genetic risk alleles that have a higher frequency in Hispanic/Latino populations and are associated with increased Indigenous American ancestry were associated with both ALL susceptibility and relapse risk ${ }^{[139]}$. In another example, the GATA3 risk SNP rs3824662, associated with Indigenous American ancestry ${ }^{[138]}$ and Ph-like ALL, has been found additionally to contribute to the increased risk of relapse in both childhood ${ }^{[21,154]}$ and adult ALL patients ${ }^{[155]}$.

Two variants in TPMT (rs1142345) and NUDT15 (rs116855232) have been discovered by GWAS to be strongly associated with thiopurine intolerance during therapy resulting in excessive toxicity in children with ALL ${ }^{[142]}$. The TPMT variant is most prevalent in Blacks and least common in East Asians ${ }^{[142]}$. The NUDT15 variant is most prevalent in East Asians, followed by Hispanics/Latinos, and extremely rare in NHWs and Blacks ${ }^{[142]}$. In a recent sequencing study, 4 additional germline loss-of-function variants were identified in NUDT15 that confer a major risk for thiopurine intolerance, and appear to be highly prevalent in East Asians, South Asians and Indigenous American populations ${ }^{[156]}$.

Moreover, a study of children with high-risk B-ALL enrolled in COG clinical trials revealed 19 genetic loci associated with increased relapse risk, of which 12 were specific to an ancestry group, including 7 SNPs specific to Hispanics/Latinos and 3 SNPs specific to Black patients ${ }^{[152]}$. These loci are associated with pharmacokinetic and pharmacodynamic phenotypes (e.g., resistance or rapid clearance of chemotherapy ${ }^{[152]}$. Further, including ancestry-specific SNPs in multivariate models of relapse risk significantly attenuated the increased risk of relapse in Hispanic/Latino and Black patients compared to white patients ${ }^{[152]}$. 


\section{Environmental exposures and ALL risk}

Genetic variation undoubtedly contributes to the racial/ethnic disparities in ALL risk and outcomes, but non-genetic factors also play an important role. In terms of the natural history of the disease, it has been proposed that childhood ALL, in particular B-ALL, follows a "two-hit" model of leukemogenesis ${ }^{[4,157]}$, with in utero development of a pre-leukemic clone ${ }^{[158,159]}$ that progresses to overt leukemia following postnatal acquisition of secondary genetic changes ${ }^{[160]}$. A lack of microbial infectious exposure perinatally or in infancy impacts immune function ${ }^{[161-163]}$, and this in combination with delayed exposure to infections may lead to abnormal immune responses that result in secondary somatic events that drive leukemogenesis ${ }^{[45]}$. This is supported by epidemiological evidence, including from studies that have assessed the impact of early-life infectious exposure on ALL risk, using proxies such as day-care attendance ${ }^{[164-166]}$, birth $\operatorname{order}^{[166-168]}$, and timing of birth ${ }^{[168]}$. Intriguingly, day-care attendance and higher birth order have been found to have a protective effect on ALL risk among NHWs supporting the "delayed infection" hypothesis ${ }^{[45]}$, but not in Hispanic/Latino children ${ }^{[164-166,168]}$. On the other hand, Caesarean section and in utero CMV infection, found to be risk factors for childhood ALL, conferred a more prominent effect in Hispanics/Latinos compared to NHWs ${ }^{[169-171]}$. As described above, several genetic variants and high-risk cytogenetic features are more prevalent in Hispanics/Latinos and are correlated with Indigenous American ancestry. More studies are needed to investigate the joint effects of both genetic and environmental risk factors and their potential interactions, particularly in Hispanics/Latinos.

\section{Socioeconomic status and ALL risk and survival}

Socioeconomic status (SES) also correlates with the racial/ethnic disparities in ALL risk. For example, in a recent study, when adjusting for percent foreign-born in areas, neighborhood SES was inversely associated with the AAIR of ALL among NHWs and Blacks, but was positively associated with ALL AAIR in Hispanics/Latinos across all age groups ${ }^{[6]}{ }^{[6]}$ This observed racial/ethnic difference in the relationship between SES and the risk of ALL was reported to be largely driven by data from California ${ }^{[6]]}$, where there was an excessive ALL risk in Los Angeles County and a highly diverse population in which Hispanics/Latinos are of an elevated Indigenous American ancestry. This contrasts with another study conducted in children without adjusting for percent foreign-born, in which they found a higher incidence of ALL among lower SES populations for Hispanics/Latinos, but among higher SES populations for other races/ethnicities ${ }^{[172]}$. One potential reason that leads to this difference is that the former study additionally controlled for percent foreign-born, which is a crucial indicator of the "Hispanic paradox" ${ }^{[100,101]}$, and represents a variety of potential underlying risk factors that may differ by individual and racial/ethnic group.

On the other hand, low SES is consistently associated with poor outcomes in ALL patients. Living in high poverty areas has been associated with high rates of relapse in childhood ALL patient ${ }^{[173]}$. Children with ALL in the United States residing in neighborhoods with the highest poverty rate have been found to have an almost 2-fold increase in mortality compared with those in neighborhoods with the lowest poverty rate $\left[\mathrm{HR}=1.8\right.$ (95\% CI: 1.41-2.30)], when adjusting for sex, age at diagnosis, race/ethnicity, and treatment era ${ }^{[174]}$. Moreover, the difference in 5-year overall survival comparing NHW children with ALL residing in the lowest poverty neighborhoods $v s$. Black patients residing in the highest poverty neighborhoods can be as high as $22 \%^{[174]}$. Furthermore, in SEER data, SES as measured at the neighborhood level significantly mediated the association between race/ethnicity and childhood ALL survival, leading to a $44 \%$ reduction from the total to the direct effect of the Black-NHW survival disparity and $31 \%$ reduction of the Hispanic/Latino-NHW disparity in survival ${ }^{[175]}$. The inferior outcomes in high poverty neighborhoods might be attributable to multiple elements, including a poor adherence to therapy (e.g., long-term oral administration of antimetabolites $)^{[176,177]}$, lack of insurance, and the discontinuous coverage of insurance ${ }^{[178-180]}$. 


\section{Access to care}

Previous studies have shown that older age was associated with less treatment adherence ${ }^{[80]}$, and that compliance with therapy was more problematic for AYAs than for other age groups ${ }^{[181-183]}$; however, the heterogeneity by race/ethnicity has been investigated mostly in childhood ALL patients. Lower exposure to mercaptopurine increases the risk of relapse in ALL, and thus the increased risk of relapse in Hispanic/Latino children with ALL compared with NHW children with ALL may in part result from a lower compliance to oral mercaptopurine therapy ${ }^{[184]}$. In a 6-month adherence monitoring program of 327 patients with ALL, Hispanic/Latino children had a significantly lower level of adherence along with lower SES compared to NHW children ${ }^{[177]}$. In another 5-month follow-up study among children with ALL from COG, adherence rates for oral 6-mercaptopurine were significantly lower in Blacks (87\%) and Asian Americans (90\%), as compared to NHWs (95\%), after adjusting for SES ${ }^{[185]}$. These suggest that compliance to therapy could be explained by factors other than SES. In addition, the type of insurance payer is a significant predictor of adherence among ALL patients. It has been found that ALL patients with commercial insurance payers had significantly higher levels of adherence compared to those with Medicaid ${ }^{[186]}$. Compared to other age groups, the AYA group is less likely to have insurance, with around $40 \%$ of individuals between 19 and 29 years old being uninsured ${ }^{[187]}$. Hispanic/Latino and Black adult patients with cancer are more likely to be uninsured or Medicaid-insured than NHW adult patients ${ }^{[180]}$. A pediatric cancer study has also demonstrated that Hispanic/Latino patients were less likely to have insurance ${ }^{[188]}$. Notably, despite that Black children with ALL were significantly more likely to have high-risk prognostic profiles compared to NHW children, it has been found that with equal access to effective antileukemic therapy, Blacks and NHWs had the same high rate of cure ${ }^{[189]}$.

\section{Recruitment to clinical trials}

In addition to the elevated incidence of Ph-like ALL in AYA ALL patients ${ }^{[96-99]}$, potential factors that contribute to the AYA "survival cliff" also include the transition from pediatric to adult treatment regimens $s^{[110]}$ and the low recruitment rate of AYA patients into clinical trials ${ }^{[190]}$. For instance, a drop off in clinical trial accruals for ALL has been identified during age 16-24, where the estimated treatment trial accrual proportion decreased dramatically from $50 \%$ at age 16 to below $10 \%$ at age 24 during $2000-2014^{[190]}$. This pattern strongly suggests that the AYA survival cliff could be in fact largely due to an "accrual cliff", as survival has been found to strongly correlate with trial accrual ${ }^{[190]}$. Moreover, there was a lack of improvement in ALL survival in patients aged 20-29 years since 1989 (APC = 0.33, $P=0.39$ ), corresponding to the negligible increase of trial accrual in AYAs during 2000-2015 ${ }^{[190]}$. In addition to AYAs, elderly ALL patients are rarely eligible for clinical trials and are underrepresented in trials of new cancer therapy ${ }^{[191,192]}$, and the underrepresentation in clinical trials for cancer therapies has been found to underlie the poor outcomes of elderly patients ${ }^{[192]}$. In addition to age disparities, Black AYA cancer patients are less likely to be enrolled on a clinical trial compared to NHW AYAs ${ }^{[193]}$, and NHWs continue to comprise the majority of participants in these trials ${ }^{[194]}$.

\section{CONCLUSIONS AND FUTURE DIRECTIONS}

In this review, we described racial/ethnic disparities in ALL risk and survival; evaluated how these vary across the age spectrum; and examined the potential causes of these disparities, including genetic and nongenetic risk factors. Genetic risk factors certainly play a significant role in contributing to these disparities, as several ALL risk loci are associated with genetic ancestry, and have demonstrated different risk allele frequencies and/or effect sizes across population groups. In particular, multiple studies have shown that $\mathrm{Ph}$ like ALL is associated with poor survival in both children and adults, and the risk of Ph-like ALL is associated with specific GATA3 risk alleles that occur more frequently in Hispanics/Latinos with elevated Indigenous American ancestry. A variety of genomic aberrations have been discovered underlying Ph-like ALL and are likely to be drivers of leukemogenesis ${ }^{[195]}$, which offers a great opportunity for precision 
medicine approaches to use molecule inhibitors targeted at these lesions. Racial/ethnic categories in epidemiologic studies also capture, albeit imperfectly, the influence from bias, racial discrimination, culture, socioeconomic status, access to care, and environmental factors ${ }^{[60]}$. In this review, we recognize that these non-genetic factors are associated with the disparities in ALL risk and survival. Improving survival in Hispanic/Latino and Black patients with ALL will require both improved access to care and inclusion of more diverse populations in future clinical trials and genetic studies.

\section{DECLARATIONS}

\section{Authors' contributions}

Researched the literature and prepared the paper: Xu K, de Smith AJ

Made substantial contributions to the discussion of content and reviewing/editing of the manuscript before submission: Xu K, Feng Q, Wiemels JL, de Smith AJ

\section{Availability of data and materials}

NHGRI-EBI GWAS Catalog data are available at https://www.ebi.ac.uk/gwas/docs/file-downloads. Genetic variants associated with ALL risk and outcomes illustrated in the PhenoGram plots [Figure 2] are available at: https://github.com/XUKEREN/jtgg_data.

\section{Financial support and sponsorship}

This work was supported by start-up funds provided by the Center for Genetic Epidemiology at the Keck School of Medicine of the University of Southern California (USC) (A.J.D.).

\section{Conflicts of interest}

All authors declared that there are no conflicts of interest.

\section{Ethical approval and consent to participate}

Not applicable.

\section{Consent for publication}

Not applicable.

\section{Copyright}

(c) The author(s) 2021.

\section{REFERENCES}

1. Paul S, Kantarjian H, Jabbour EJ. Adult acute lymphoblastic leukemia. Mayo Clin Proc 2016;91:1645-66. DOI PubMed

2. Hunger SP, Mullighan CG. Acute lymphoblastic leukemia in children. N Engl J Med 2015;373:1541-52. DOI PubMed

3. Howlader N, Noone AM, Krapcho M, et al. SEER Cancer Statistics Review 1975-2017. Available from: https://seer.cancer.gov/csr/1975_2017/. [Last accessed on 15 Jun 2021].

4. Siegel RL, Miller KD, Fuchs HE, Jemal A. Cancer Statistics, 2021. CA Cancer J Clin 2021;71:7-33. DOI PubMed

5. Dores GM, Devesa SS, Curtis RE, Linet MS, Morton LM. Acute leukemia incidence and patient survival among children and adults in the United States, 2001-2007. Blood 2012;119:34-43. DOI PubMed PMC

6. Ward E, DeSantis C, Robbins A, Kohler B, Jemal A. Childhood and adolescent cancer statistics, 2014. CA Cancer J Clin 2014;64:83103. DOI PubMed

7. Williams LA, Yang JJ, Hirsch BA, Marcotte EL, Spector LG. Is there etiologic heterogeneity between subtypes of childhood acute lymphoblastic leukemia? Cancer Epidemiol Biomarkers Prev 2019;28:846-56. DOI PubMed PMC

8. Wiemels J. Perspectives on the causes of childhood leukemia. Chem Biol Interact 2012;196:59-67. DOI PubMed PMC

9. Preston DL, Kusumi S, Tomonaga M, et al. Cancer incidence in atomic bomb survivors. Part III: leukemia, lymphoma and multiple myeloma, 1950-1987. Radiat Res 1994;137:S68-97. PubMed

10. Doll R, Wakeford R. Risk of childhood cancer from fetal irradiation. Br J Radiol 1997;70:130-9. DOI PubMed

11. Bartley K, Metayer C, Selvin S, Ducore J, Buffler P. Diagnostic X-rays and risk of childhood leukaemia. Int J Epidemiol 2010;39:1628-37. DOI PubMed PMC

12. Linet MS, Kim KP, Rajaraman P. Children's exposure to diagnostic medical radiation and cancer risk: epidemiologic and dosimetric 
considerations. Pediatr Radiol 2009;39 Suppl 1:S4-26. DOI PubMed PMC

13. Curtin K, Smith KR, Fraser A, Pimentel R, Kohlmann W, Schiffman JD. Familial risk of childhood cancer and tumors in the LiFraumeni spectrum in the Utah Population Database: implications for genetic evaluation in pediatric practice. Int $J$ Cancer 2013;133:2444-53. DOI PubMed PMC

14. Klco JM, Mullighan CG. Advances in germline predisposition to acute leukaemias and myeloid neoplasms. Nat Rev Cancer 2021;21:122-37. DOI PubMed

15. Treviño LR, Yang W, French D, et al. Germline genomic variants associated with childhood acute lymphoblastic leukemia. Nat Genet 2009;41:1001-5. DOI PubMed PMC

16. Papaemmanuil E, Hosking FJ, Vijayakrishnan J, et al. Loci on 7p12.2, 10q21.2 and 14q11.2 are associated with risk of childhood acute lymphoblastic leukemia. Nat Genet 2009;41:1006-10. DOI PubMed PMC

17. Sherborne AL, Hosking FJ, Prasad RB, et al. Variation in CDKN2A at 9p21.3 influences childhood acute lymphoblastic leukemia risk. Nat Genet 2010;42:492-4. DOI PubMed PMC

18. Ellinghaus E, Stanulla M, Richter G, et al. Identification of germline susceptibility loci in ETV6-RUNX1-rearranged childhood acute lymphoblastic leukemia. Leukemia 2012;26:902-9. DOI PubMed PMC

19. Xu H, Yang W, Perez-Andreu V, et al. Novel susceptibility variants at 10p12.31-12.2 for childhood acute lymphoblastic leukemia in ethnically diverse populations. J Natl Cancer Inst 2013;105:733-42. DOI PubMed PMC

20. Migliorini G, Fiege B, Hosking FJ, et al. Variation at 10p12.2 and 10p14 influences risk of childhood B-cell acute lymphoblastic leukemia and phenotype. Blood 2013;122:3298-307. DOI PubMed

21. Perez-Andreu V, Roberts KG, Harvey RC, et al. Inherited GATA3 variants are associated with Ph-like childhood acute lymphoblastic leukemia and risk of relapse. Nat Genet 2013;45:1494-8. DOI PubMed PMC

22. Walsh KM, de Smith AJ, Hansen HM, et al. A heritable missense polymorphism in CDKN2A confers strong risk of childhood acute lymphoblastic leukemia and is preferentially selected during clonal evolution. Cancer Res 2015;75:4884-94. DOI PubMed PMC

23. Hungate EA, Vora SR, Gamazon ER, et al. A variant at 9p21.3 functionally implicates CDKN2B in paediatric B-cell precursor acute lymphoblastic leukaemia aetiology. Nat Commun 2016;7:10635. DOI PubMed PMC

24. Vijayakrishnan J, Kumar R, Henrion MY, et al. A genome-wide association study identifies risk loci for childhood acute lymphoblastic leukemia at 10q26.13 and 12q23.1. Leukemia 2017;31:573-9. DOI PubMed PMC

25. Clay-Gilmour AI, Hahn T, Preus LM, et al. Genetic association with B-cell acute lymphoblastic leukemia in allogeneic transplant patients differs by age and sex. Blood Adv 2017;1:1717-28. DOI PubMed PMC

26. Wiemels JL, Walsh KM, de Smith AJ, et al. GWAS in childhood acute lymphoblastic leukemia reveals novel genetic associations at chromosomes 17q12 and 8q24.21. Nat Commun 2018;9:286. DOI PubMed PMC

27. Vijayakrishnan J, Studd J, Broderick P, et al; PRACTICAL Consortium. Genome-wide association study identifies susceptibility loci for B-cell childhood acute lymphoblastic leukemia. Nat Commun 2018;9:1340. DOI PubMed PMC

28. de Smith AJ, Walsh KM, Francis SS, et al. BMI1 enhancer polymorphism underlies chromosome 10p12.31 association with childhood acute lymphoblastic leukemia. Int J Cancer 2018;143:2647-58. DOI PubMed PMC

29. Qian M, Xu H, Perez-Andreu V, et al. Novel susceptibility variants at the ERG locus for childhood acute lymphoblastic leukemia in Hispanics. Blood 2019;133:724-9. DOI PubMed PMC

30. Qian M, Zhao X, Devidas M, et al. Genome-wide association study of susceptibility loci for T-cell acute lymphoblastic leukemia in children. J Natl Cancer Inst 2019;111:1350-7. DOI PubMed PMC

31. de Smith AJ, Walsh KM, Morimoto LM, et al. Heritable variation at the chromosome 21 gene ERG is associated with acute lymphoblastic leukemia risk in children with and without Down syndrome. Leukemia 2019;33:2746-51. DOI PubMed PMC

32. Vijayakrishnan J, Qian M, Studd JB, et al. Identification of four novel associations for B-cell acute lymphoblastic leukaemia risk. Nat Commun 2019;10:5348. DOI PubMed PMC

33. Shah S, Schrader KA, Waanders E, et al. A recurrent germline PAX5 mutation confers susceptibility to pre-B cell acute lymphoblastic leukemia. Nat Genet 2013;45:1226-31. DOI PubMed PMC

34. Gu Z, Churchman ML, Roberts KG, et al. PAX5-driven subtypes of B-progenitor acute lymphoblastic leukemia. Nat Genet 2019;51:296-307. DOI PubMed PMC

35. Noetzli L, Lo RW, Lee-Sherick AB, et al. Germline mutations in ETV6 are associated with thrombocytopenia, red cell macrocytosis and predisposition to lymphoblastic leukemia. Nat Genet 2015;47:535-8. DOI PubMed PMC

36. Zhang MY, Churpek JE, Keel SB, et al. Germline ETV6 mutations in familial thrombocytopenia and hematologic malignancy. Nat Genet 2015;47:180-5. DOI PubMed PMC

37. Moriyama T, Metzger ML, Wu G, et al. Germline genetic variation in ETV6 and risk of childhood acute lymphoblastic leukaemia: a systematic genetic study. Lancet Oncol 2015;16:1659-66. DOI PubMed PMC

38. Melazzini F, Palombo F, Balduini A, et al. Clinical and pathogenic features of ETV6-related thrombocytopenia with predisposition to acute lymphoblastic leukemia. Haematologica 2016;101:1333-42. DOI PubMed PMC

39. Nishii R, Baskin-Doerfler R, Yang W, et al. Molecular basis of ETV6-mediated predisposition to childhood acute lymphoblastic leukemia. Blood 2021;137:364-73. DOI PubMed PMC

40. Kuehn HS, Boisson B, Cunningham-Rundles C, et al. Loss of B cells in patients with heterozygous mutations in IKAROS. $N$ Engl $J$ Med 2016;374:1032-43. DOI PubMed PMC

41. Yoshida N, Sakaguchi H, Muramatsu H, et al. Germline IKAROS mutation associated with primary immunodeficiency that progressed to T-cell acute lymphoblastic leukemia. Leukemia 2017;31:1221-3. DOI PubMed

42. Churchman ML, Qian M, Te Kronnie G, et al. Germline genetic IKZF1 variation and predisposition to childhood acute lymphoblastic 
leukemia. Cancer Cell 2018;33:937-48.e8. DOI PubMed PMC

43. Holmfeldt L, Wei L, Diaz-Flores E, et al. The genomic landscape of hypodiploid acute lymphoblastic leukemia. Nat Genet 2013;45:242-52. DOI PubMed PMC

44. Qian M, Cao X, Devidas M, et al. TP53 germline variations influence the predisposition and prognosis of B-cell acute lymphoblastic leukemia in children. J Clin Oncol 2018;36:591-9. DOI PubMed PMC

45. Greaves M. A causal mechanism for childhood acute lymphoblastic leukaemia. Nat Rev Cancer 2018;18:471-84. DOI PubMed PMC

46. Whitehead TP, Metayer C, Wiemels JL, Singer AW, Miller MD. Childhood leukemia and primary prevention. Curr Probl Pediatr Adolesc Health Care 2016;46:317-52. DOI PubMed PMC

47. Liu R, Zhang L, McHale CM, Hammond SK. Paternal smoking and risk of childhood acute lymphoblastic leukemia: systematic review and meta-analysis. J Oncol 2011;2011:854584. DOI PubMed PMC

48. Metayer C, Zhang L, Wiemels JL, et al. Tobacco smoke exposure and the risk of childhood acute lymphoblastic and myeloid leukemias by cytogenetic subtype. Cancer Epidemiol Biomarkers Prev 2013;22:1600-11. DOI PubMed PMC

49. de Smith AJ, Kaur M, Gonseth S, et al. Correlates of prenatal and early-life tobacco smoke exposure and frequency of common gene deletions in childhood acute lymphoblastic leukemia. Cancer Res 2017;77:1674-83. DOI PubMed PMC

50. Bailey HD, Infante-Rivard C, Metayer C, et al. Home pesticide exposures and risk of childhood leukemia: findings from the childhood leukemia international consortium. Int J Cancer 2015;137:2644-63. DOI PubMed PMC

51. Hyland C, Gunier RB, Metayer C, Bates MN, Wesseling C, Mora AM. Maternal residential pesticide use and risk of childhood leukemia in Costa Rica. Int J Cancer 2018;143:1295-304. DOI PubMed PMC

52. Colt JS, Blair A. Parental occupational exposures and risk of childhood cancer. Environ Health Perspect 1998;106 Suppl 3:909-25. DOI PubMed PMC

53. Bailey HD, Metayer C, Milne E, et al. Home paint exposures and risk of childhood acute lymphoblastic leukemia: findings from the Childhood Leukemia International Consortium. Cancer Causes Control 2015;26:1257-70. DOI PubMed PMC

54. Ward MH, Colt JS, Deziel NC, et al. Residential levels of polybrominated diphenyl ethers and risk of childhood acute lymphoblastic leukemia in California. Environ Health Perspect 2014;122:1110-6. DOI PubMed PMC

55. Boothe VL, Boehmer TK, Wendel AM, Yip FY. Residential traffic exposure and childhood leukemia: a systematic review and metaanalysis. Am J Prev Med 2014;46:413-22. DOI PubMed PMC

56. Whitehead TP, Ward MH, Colt JS, et al. Dust metal loadings and the risk of childhood acute lymphoblastic leukemia. J Expo Sci Environ Epidemiol 2015;25:593-8. DOI PubMed PMC

57. Karczewski KJ, Francioli LC, Tiao G, et al; Genome Aggregation Database Consortium. The mutational constraint spectrum quantified from variation in 141,456 humans. Nature 2020;581:434-43. DOI PubMed PMC

58. Wang K, Li M, Hakonarson H. ANNOVAR: functional annotation of genetic variants from high-throughput sequencing data. Nucleic Acids Res 2010;38:e164. DOI PubMed PMC

59. Borrell LN, Elhawary JR, Fuentes-Afflick E, et al. Race and genetic ancestry in medicine-A time for reckoning with racism. $N$ Engl $J$ Med 2021;384:474-80. DOI PubMed

60. Borrell LN, Elhawary JR, Fuentes-Afflick E, et al. Race and genetic ancestry in medicine - a time for reckoning with racism. $N$ Engl $J$ Med 2021;384:474-80. DOI PubMed

61. Alvidrez J, Castille D, Laude-Sharp M, Rosario A, Tabor D. The national institute on minority health and health disparities research framework. Am J Public Health 2019;109:S16-20. DOI PubMed PMC

62. Barrington-Trimis JL, Cockburn M, Metayer C, Gauderman WJ, Wiemels J, McKean-Cowdin R. Rising rates of acute lymphoblastic leukemia in Hispanic children: trends in incidence from 1992 to 2011. Blood 2015;125:3033-4. DOI PubMed PMC

63. Giddings BM, Whitehead TP, Metayer C, Miller MD. Childhood leukemia incidence in California: high and rising in the Hispanic population. Cancer 2016;122:2867-75. DOI PubMed PMC

64. Barrington-Trimis JL, Cockburn M, Metayer C, Gauderman WJ, Wiemels J, McKean-Cowdin R. Trends in childhood leukemia incidence over two decades from 1992 to 2013. Int J Cancer 2017;140:1000-8. DOI PubMed PMC

65. Siegel DA, Henley SJ, Li J, Pollack LA, Van Dyne EA, White A. Rates and trends of pediatric acute lymphoblastic leukemia - United States, 2001-2014. MMWR Morb Mortal Wkly Rep 2017;66:950-4. DOI PubMed PMC

66. Feng Q, de Smith AJ, Vergara-Lluri M, et al. Trends in acute lymphoblastic leukemia incidence in the United States by race/ethnicity from 2000 to 2016. Am J Epidemiol 2021;190:519-27. DOI PubMed

67. Pui CH, Evans WE. A 50-year journey to cure childhood acute lymphoblastic leukemia. Semin Hematol 2013;50:185-96. DOI PubMed PMC

68. Alvarnas JC, Brown PA, Aoun P, et al. Acute lymphoblastic leukemia, version 2.2015. J Natl Compr Canc Netw 2015;13:1240-79. DOI PubMed

69. Mohseni M, Uludag H, Brandwein JM. Advances in biology of acute lymphoblastic leukemia (ALL) and therapeutic implications. Am J Blood Res 2018;8:29-56. PubMed PMC

70. Carobolante F, Chiaretti S, Skert C, Bassan R. Practical guidance for the management of acute lymphoblastic leukemia in the adolescent and young adult population. Ther Adv Hematol 2020;11:2040620720903531. DOI PubMed PMC

71. American Cancer Society. Cancer Facts \& Figures 2020. Available from: https://www.cancer.org/content/dam/cancer$\mathrm{org} /$ research/cancer-facts-and-statistics/annual-cancer-facts-and-figures/2020/cancer-facts-and-figures-2020.pdf. [Last accessed on 15 Jun 2021].

72. Inaba H, Mullighan CG. Pediatric acute lymphoblastic leukemia. Haematologica 2020;105:2524-39. DOI PubMed PMC 
73. Rytting ME, Thomas DA, O'Brien SM, et al. Augmented Berlin-Frankfurt-Münster therapy in adolescents and young adults (AYAs) with acute lymphoblastic leukemia (ALL). Cancer 2014;120:3660-8. DOI PubMed PMC

74. Stock W, Luger SM, Advani AS, et al. Favorable outcomes for older adolescents and young adults (AYA) with acute lymphoblastic leukemia (ALL): early results of U.S. intergroup trial C10403. Blood 2014;124:796. DOI

75. DeAngelo DJ, Stevenson KE, Dahlberg SE, et al. Long-term outcome of a pediatric-inspired regimen used for adults aged 18-50 years with newly diagnosed acute lymphoblastic leukemia. Leukemia 2015;29:526-34. DOI PubMed PMC

76. Rytting ME, Jabbour EJ, Jorgensen JL, et al. Final results of a single institution experience with a pediatric-based regimen, the augmented Berlin-Frankfurt-Münster, in adolescents and young adults with acute lymphoblastic leukemia, and comparison to the hyper-CVAD regimen. Am J Hematol 2016;91:819-23. DOI PubMed PMC

77. Sive JI, Buck G, Fielding A, et al. Outcomes in older adults with acute lymphoblastic leukaemia (ALL): results from the international MRC UKALL XII/ECOG2993 trial. Br J Haematol 2012;157:463-71. DOI PubMed PMC

78. Pulte D, Jansen L, Gondos A, et al; GEKID Cancer Survival Working Group. Survival of adults with acute lymphoblastic leukemia in Germany and the United States. PLoS One 2014;9:e85554. DOI PubMed PMC

79. Bailey C, Richardson LC, Allemani C, et al; CONCORD Working Group (US members). Adult leukemia survival trends in the United States by subtype: A population-based registry study of 370,994 patients diagnosed during 1995-2009. Cancer 2018;124:3856-67. DOI PubMed PMC

80. Huguet F, Chevret S, Leguay T, et al; Group of Research on Adult ALL (GRAALL). Intensified therapy of acute lymphoblastic leukemia in adults: report of the randomized GRAALL-2005 clinical trial. J Clin Oncol 2018;36:2514-23. DOI PubMed

81. O'Dwyer KM, Liesveld JL. Philadelphia chromosome negative B-cell acute lymphoblastic leukemia in older adults: Current treatment and novel therapies. Best Pract Res Clin Haematol 2017;30:184-92. DOI PubMed

82. Luskin MR, Deangelo DJ. Mini-Hyper-CVD combinations for older adults: results of recent trials and a glimpse into the future. Clin Lymphoma Myeloma Leuk 2020;20:S44-7. DOI PubMed

83. Wang L, Bhatia S, Gomez SL, Yasui Y. Differential inequality trends over time in survival among U.S. children with acute lymphoblastic leukemia by race/ethnicity, age at diagnosis, and sex. Cancer Epidemiol Biomarkers Prev 2015;24:1781-8. DOI PubMed PMC

84. Goggins WB, Lo FF. Racial and ethnic disparities in survival of US children with acute lymphoblastic leukemia: evidence from the SEER database 1988-2008. Cancer Causes Control 2012;23:737-43. DOI PubMed

85. Kahn JM, Keegan TH, Tao L, Abrahão R, Bleyer A, Viny AD. Racial disparities in the survival of American children, adolescents, and young adults with acute lymphoblastic leukemia, acute myelogenous leukemia, and Hodgkin lymphoma. Cancer 2016;122:272330. DOI PubMed PMC

86. Kahn JM, Cole PD, Blonquist TM, et al. An investigation of toxicities and survival in Hispanic children and adolescents with ALL: results from the Dana-Farber Cancer Institute ALL Consortium protocol 05-001. Pediatr Blood Cancer 2018;65:e26871. DOI PubMed PMC

87. Abrahão R, Lichtensztajn DY, Ribeiro RC, et al. Racial/ethnic and socioeconomic disparities in survival among children with acute lymphoblastic leukemia in California, 1988-2011: A population-based observational study. Pediatr Blood Cancer 2015;62:1819-25. DOI PubMed

88. Murphy CC, Lupo PJ, Roth ME, Winick NJ, Pruitt SL. Disparities in cancer survival among adolescents and young adults: a population-based study of 88,000 patients. J Natl Cancer Inst ;2021:djab006. DOI PubMed

89. Pulte D, Redaniel MT, Jansen L, Brenner H, Jeffreys M. Recent trends in survival of adult patients with acute leukemia: overall improvements, but persistent and partly increasing disparity in survival of patients from minority groups. Haematologica 2013;98:222-9. DOI PubMed PMC

90. Quiroz E, Aldoss I, Pullarkat V, Rego E, Marcucci G, Douer D. The emerging story of acute lymphoblastic leukemia among the Latin American population - biological and clinical implications. Blood Rev 2019;33:98-105. DOI PubMed

91. Pérez-Saldivar ML, Fajardo-Gutiérrez A, Bernáldez-Ríos R, et al. Childhood acute leukemias are frequent in Mexico City: descriptive epidemiology. BMC Cancer 2011;11:355. DOI PubMed PMC

92. Santamaría-Quesada C, Vargas M, Venegas P, et al. Molecular and epidemiologic findings of childhood acute leukemia in Costa Rica. J Pediatr Hematol Oncol 2009;31:131-5. DOI PubMed

93. Moore KJ, Hubbard AK, Williams LA, Spector LG. Childhood cancer incidence among specific Asian and Pacific Islander populations in the United States. Int J Cancer 2020;147:3339-48. DOI PubMed PMC

94. Shah N, Rockwell B, Kazemi M, et al. Ethnic disparities in survival of adult B-cell acute lymphoblastic leukemia in modern era - a SEER analysis. Leuk Lymphoma 2020;61:3503-6. DOI PubMed

95. Chiaretti S, Messina M, Della Starza I, et al. Philadelphia-like acute lymphoblastic leukemia is associated with minimal residual disease persistence and poor outcome. First report of the minimal residual disease-oriented GIMEMA LAL1913. Haematologica 2021;106:1559-68. DOI PubMed PMC

96. Roberts KG, Li Y, Payne-Turner D, et al. Targetable kinase-activating lesions in Ph-like acute lymphoblastic leukemia. $N$ Engl J Med 2014;371:1005-15. DOI PubMed PMC

97. Herold T, Baldus CD, Gökbuget N. Ph-like acute lymphoblastic leukemia in older adults. N Engl J Med 2014;371:2235. DOI PubMed

98. Roberts KG, Gu Z, Payne-Turner D, et al. High frequency and poor outcome of Philadelphia chromosome-like acute lymphoblastic leukemia in adults. J Clin Oncol 2017;35:394-401. DOI PubMed PMC

99. Jain N, Roberts KG, Jabbour E, et al. Ph-like acute lymphoblastic leukemia: a high-risk subtype in adults. Blood 2017;129:572-81. 
DOI PubMed PMC

100. Young RP, Hopkins RJ. A review of the Hispanic paradox: time to spill the beans? Eur Respir Rev 2014;23:439-49. DOI PubMed

101. Franzini L, Ribble JC, Keddie AM. Understanding the Hispanic paradox. Ethn Dis 2011;11:496-518. PubMed

102. Swan J, Edwards BK. Cancer rates among American Indians and Alaska Natives: is there a national perspective. Cancer 2003;98:1262-72. DOI PubMed

103. Nathan PC, Wasilewski-Masker K, Janzen LA. Long-term outcomes in survivors of childhood acute lymphoblastic leukemia. Hematol Oncol Clin North Am 2009;23:1065-82, vi. DOI PubMed

104. Essig S, Li Q, Chen Y, et al. Risk of late effects of treatment in children newly diagnosed with standard-risk acute lymphoblastic leukaemia: a report from the Childhood Cancer Survivor Study cohort. Lancet Oncol 2014;15:841-51. DOI PubMed PMC

105. Gofman I, Ducore J. Risk factors for the development of obesity in children surviving ALL and NHL. J Pediatr Hematol Oncol 2009;31:101-7. DOI PubMed

106. Sadighi ZS, Ness KK, Hudson MM, et al. Headache types, related morbidity, and quality of life in survivors of childhood acute lymphoblastic leukemia: a prospective cross sectional study. Eur J Paediatr Neurol 2014;18:722-9. DOI PubMed PMC

107. Shoag JM, Barredo JC, Lossos IS, Pinheiro PS. Acute lymphoblastic leukemia mortality in Hispanic Americans. Leuk Lymphoma 2020;61:2674-81. DOI PubMed

108. Eche IJ, Aronowitz T. A literature review of racial disparities in overall survival of black children with acute lymphoblastic leukemia compared with white children with acute lymphoblastic leukemia. J Pediatr Oncol Nurs 2020;37:180-94. DOI PubMed

109. Bryant C, Mayhew M, Fleites J, Lozano J, Saunders JM. Comparison of five-year survival rate between black and white children with acute lymphoblastic leukemia. Cureus 2020;12:e11797. DOI PubMed PMC

110. Siegel SE, Stock W, Johnson RH, et al. Pediatric-inspired treatment regimens for adolescents and young adults with philadelphia chromosome-negative acute lymphoblastic leukemia: a review. JAMA Oncol 2018;4:725-34. DOI PubMed PMC

111. National Cancer Institute. Cancer Stat Facts: leukemia - acute lymphocytic leukemia (ALL). Available from: https://seer.cancer.gov/statfacts/html/alyl.html. [Last accessed on 15 Jun 2021].

112. Burmeister T, Schwartz S, Bartram CR, Gökbuget N, Hoelzer D, Thiel E; GMALL study group. Patients' age and BCR-ABL frequency in adult B-precursor ALL: a retrospective analysis from the GMALL study group. Blood 2008;112:918-9. DOI PubMed

113. Byun JM, Koh Y, Shin DY, et al; Korean Adult ALL Working Party; Korean Society of Hematology. BCR-ABL translocation as a favorable prognostic factor in elderly patients with acute lymphoblastic leukemia in the era of potent tyrosine kinase inhibitors. Haematologica 2017;102:e187-90. DOI PubMed PMC

114. Moorman AV, Chilton L, Wilkinson J, Ensor HM, Bown N, Proctor SJ. A population-based cytogenetic study of adults with acute lymphoblastic leukemia. Blood 2010;115:206-14. DOI PubMed

115. Paulsson K, Lilljebjörn H, Biloglav A, et al. The genomic landscape of high hyperdiploid childhood acute lymphoblastic leukemia. Nat Genet 2015;47:672-6. DOI PubMed

116. Geyer MB, Hsu M, Devlin SM, Tallman MS, Douer D, Park JH. Overall survival among older US adults with ALL remains low despite modest improvement since 1980: SEER analysis. Blood 2017;129:1878-81. DOI PubMed PMC

117. Bassan R, Bourquin JP, DeAngelo DJ, Chiaretti S. New approaches to the management of adult acute lymphoblastic leukemia. J Clin Oncol 2018:JCO2017773648. DOI PubMed

118. Wenzinger C, Williams E, Gru AA. Updates in the pathology of precursor lymphoid neoplasms in the revised fourth edition of the WHO classification of tumors of hematopoietic and lymphoid tissues. Curr Hematol Malig Rep 2018;13:275-88. DOI PubMed

119. Iacobucci I, Mullighan CG. Genetic basis of acute lymphoblastic leukemia. J Clin Oncol 2017;35:975-83. DOI PubMed PMC

120. You MJ, Medeiros LJ, Hsi ED. T-lymphoblastic leukemia/lymphoma. Am J Clin Pathol 2015;144:411-22. DOI PubMed

121. Rowe JM, Buck G, Burnett AK, et al; ECOG; MRC/NCRI Adult Leukemia Working Party. Induction therapy for adults with acute lymphoblastic leukemia: results of more than 1500 patients from the international ALL trial: MRC UKALL XII/ECOG E2993. Blood 2005;106:3760-7. DOI PubMed

122. Marks DI, Paietta EM, Moorman AV, et al. T-cell acute lymphoblastic leukemia in adults: clinical features, immunophenotype, cytogenetics, and outcome from the large randomized prospective trial (UKALL XII/ECOG 2993). Blood 2009;114:5136-45. DOI PubMed PMC

123. Papaemmanuil E, Rapado I, Li Y, et al. RAG-mediated recombination is the predominant driver of oncogenic rearrangement in ETV6-RUNX1 acute lymphoblastic leukemia. Nat Genet 2014;46:116-25. DOI PubMed PMC

124. Bhojwani D, Pei D, Sandlund JT, et al. ETV6-RUNX1-positive childhood acute lymphoblastic leukemia: improved outcome with contemporary therapy. Leukemia 2012;26:265-70. DOI PubMed PMC

125. Chokkalingam AP, Hsu LI, Metayer C, et al. Genetic variants in ARID5B and CEBPE are childhood ALL susceptibility loci in Hispanics. Cancer Causes Control 2013;24:1789-95. DOI PubMed PMC

126. Aldrich MC, Zhang L, Wiemels JL, et al. Cytogenetics of Hispanic and White children with acute lymphoblastic leukemia in California. Cancer Epidemiol Biomarkers Prev 2006;15:578-81. DOI PubMed

127. Kurzrock R, Kantarjian HM, Druker BJ, Talpaz M. Philadelphia chromosome-positive leukemias: from basic mechanisms to molecular therapeutics. Ann Intern Med 2003;138:819-30. DOI PubMed

128. Igwe IJ, Yang D, Merchant A, et al. The presence of Philadelphia chromosome does not confer poor prognosis in adult pre-B acute lymphoblastic leukaemia in the tyrosine kinase inhibitor era - a surveillance, epidemiology, and end results database analysis. $\mathrm{Br} J$ Haematol 2017;179:618-26. DOI PubMed PMC

129. Uckun FM, Nachman JB, Sather HN, et al. Clinical significance of Philadelphia chromosome positive pediatric acute lymphoblastic leukemia in the context of contemporary intensive therapies: a report from the Children's Cancer Group. Cancer 1998;83:2030-9. 
PubMed

130. Sawalha Y, Advani AS. Management of older adults with acute lymphoblastic leukemia: challenges \& current approaches. Int $J$ Hematol Oncol 2018;7:IJH02. DOI PubMed PMC

131. Kozlowski P, Lennmyr E, Ahlberg L, et al; Swedish Adult Acute Lymphoblastic Leukemia Group (SVALL). Age but not Philadelphia positivity impairs outcome in older/elderly patients with acute lymphoblastic leukemia in Sweden. Eur J Haematol 2017;99:141-9. DOI PubMed

132. Harvey RC, Mullighan CG, Chen IM, et al. Rearrangement of CRLF2 is associated with mutation of JAK kinases, alteration of IKZF1, Hispanic/Latino ethnicity, and a poor outcome in pediatric B-progenitor acute lymphoblastic leukemia. Blood 2010;115:5312-21. DOI PubMed PMC

133. Yang H, Zhang H, Luan Y, et al. Non-coding germline GATA3 variants alter chromatin topology and contribute to pathogenesis of acute lymphoblastic leukemia. Cancer Biology 2020. DOI

134. Herold T, Schneider S, Metzeler KH, et al. Adults with Philadelphia chromosome-like acute lymphoblastic leukemia frequently have IGH-CRLF2 and JAK2 mutations, persistence of minimal residual disease and poor prognosis. Haematologica 2017;102:130-8. DOI PubMed PMC

135. Perez-Andreu V, Roberts KG, Xu H, et al. A genome-wide association study of susceptibility to acute lymphoblastic leukemia in adolescents and young adults. Blood 2015;125:680-6. DOI PubMed PMC

136. Evans TJ, Milne E, Anderson D, et al. Confirmation of childhood acute lymphoblastic leukemia variants, ARID5B and IKZF1, and interaction with parental environmental exposures. PLoS One 2014;9:e110255. DOI PubMed PMC

137. Walsh KM, Chokkalingam AP, Hsu LI, et al. Associations between genome-wide Native American ancestry, known risk alleles and B-cell ALL risk in Hispanic children. Leukemia 2013;27:2416-9. DOI PubMed PMC

138. Walsh KM, de Smith AJ, Chokkalingam AP, et al. GATA3 risk alleles are associated with ancestral components in Hispanic children with ALL. Blood 2013;122:3385-7. DOI PubMed PMC

139. Xu H, Cheng C, Devidas M, et al. ARID5B genetic polymorphisms contribute to racial disparities in the incidence and treatment outcome of childhood acute lymphoblastic leukemia. J Clin Oncol 2012;30:751-7. DOI PubMed PMC

140. Wolfe D, Dudek S, Ritchie MD, Pendergrass SA. Visualizing genomic information across chromosomes with PhenoGram. BioData Min 2013;6:18. DOI PubMed PMC

141. Buniello A, MacArthur JAL, Cerezo M, et al. The NHGRI-EBI GWAS Catalog of published genome-wide association studies, targeted arrays and summary statistics 2019. Nucleic Acids Res 2019;47:D1005-12. DOI PubMed PMC

142. Yang JJ, Landier W, Yang W, et al. Inherited NUDT15 variant is a genetic determinant of mercaptopurine intolerance in children with acute lymphoblastic leukemia. J Clin Oncol 2015;33:1235-42. DOI PubMed PMC

143. Diouf B, Crews KR, Lew G, et al. Association of an inherited genetic variant with vincristine-related peripheral neuropathy in children with acute lymphoblastic leukemia. JAMA 2015;313:815-23. DOI PubMed PMC

144. Fernandez CA, Smith C, Yang W, et al. Genome-wide analysis links NFATC2 with asparaginase hypersensitivity. Blood 2015;126:69-75. DOI PubMed PMC

145. Liu C, Yang W, Devidas M, et al. Clinical and genetic risk factors for acute pancreatitis in patients with acute lymphoblastic leukemia. J Clin Oncol 2016;34:2133-40. DOI PubMed PMC

146. Liu Y, Fernandez CA, Smith C, et al. Genome-wide study links PNPLA3 variant with elevated hepatic transaminase after acute lymphoblastic leukemia therapy. Clin Pharmacol Ther 2017;102:131-40. DOI PubMed PMC

147. Højfeldt SG, Wolthers BO, Tulstrup M, et al; Nordic Society of Paediatric Haematology Oncology (NOPHO) group. Genetic predisposition to PEG-asparaginase hypersensitivity in children treated according to NOPHO ALL2008. Br J Haematol 2019;184:405-17. DOI PubMed

148. Liu C, Yang W, Pei D, et al. Genomewide approach validates thiopurine methyltransferase activity is a monogenic pharmacogenomic trait. Clin Pharmacol Ther 2017;101:373-81. DOI PubMed PMC

149. Tulstrup M, Grosjean M, Nielsen SN, et al. NT5C2 germline variants alter thiopurine metabolism and are associated with acquired NT5C2 relapse mutations in childhood acute lymphoblastic leukaemia. Leukemia 2018;32:2527-35. DOI PubMed

150. Yang JJ, Cheng C, Devidas M, et al. Genome-wide association study identifies germline polymorphisms associated with relapse of childhood acute lymphoblastic leukemia. Blood 2012;120:4197-204. DOI PubMed PMC

151. Spear ML, Diaz-Papkovich A, Ziv E, et al. Recent shifts in the genomic ancestry of Mexican Americans may alter the genetic architecture of biomedical traits. Elife 2020;9:e56029. DOI PubMed PMC

152. Karol SE, Larsen E, Cheng C, et al. Genetics of ancestry-specific risk for relapse in acute lymphoblastic leukemia. Leukemia 2017;31:1325-32. DOI PubMed PMC

153. Yang JJ, Cheng C, Devidas M, et al. Ancestry and pharmacogenomics of relapse in acute lymphoblastic leukemia. Nat Genet 2011;43:237-41. DOI PubMed PMC

154. Zhang H, Liu AP, Devidas M, et al. Association of GATA3 polymorphisms with minimal residual disease and relapse risk in childhood acute lymphoblastic leukemia. J Natl Cancer Inst 2021;113:408-17. DOI PubMed

155. Jain N, Zhang H, Roberts K G, et al. GATA3 rs3824662A allele is overrepresented in adult patients with Ph-like ALL, especially in patients with CRLF2 abnormalities. Blood 2017;130:1430.

156. Moriyama T, Nishii R, Perez-Andreu V, et al. NUDT15 polymorphisms alter thiopurine metabolism and hematopoietic toxicity. Nat Genet 2016;48:367-73. DOI PubMed PMC

157. Greaves M. Childhood leukaemia. BMJ 2002;324:283-7. DOI PubMed PMC

158. Wiemels J, Cazzaniga G, Daniotti M, et al. Prenatal origin of acute lymphoblastic leukaemia in children. Lancet 1999;354:1499-503. 
DOI PubMed

159. Greaves MF, Maia AT, Wiemels JL, Ford AM. Leukemia in twins: lessons in natural history. Blood 2003;102:2321-33. DOI PubMed

160. Bateman CM, Colman SM, Chaplin T, et al. Acquisition of genome-wide copy number alterations in monozygotic twins with acute lymphoblastic leukemia. Blood 2010;115:3553-8. DOI PubMed

161. Torow N, Hornef MW. The neonatal window of opportunity: setting the stage for life-long host-microbial interaction and immune homeostasis. J Immunol 2017;198:557-63. DOI PubMed

162. Olszak T, An D, Zeissig S, et al. Microbial exposure during early life has persistent effects on natural killer T cell function. Science 2012;336:489-93. DOI PubMed PMC

163. Biesbroek G, Tsivtsivadze E, Sanders EA, et al. Early respiratory microbiota composition determines bacterial succession patterns and respiratory health in children. Am J Respir Crit Care Med 2014;190:1283-92. DOI PubMed

164. Urayama KY, Buffler PA, Gallagher ER, Ayoob JM, Ma X. A meta-analysis of the association between day-care attendance and childhood acute lymphoblastic leukaemia. Int J Epidemiol 2010;39:718-32. DOI PubMed PMC

165. Ma X, Buffler PA, Wiemels JL, et al. Ethnic difference in daycare attendance, early infections, and risk of childhood acute lymphoblastic leukemia. Cancer Epidemiol Biomarkers Prev 2005;14:1928-34. DOI PubMed

166. Urayama KY, Ma X, Selvin S, et al. Early life exposure to infections and risk of childhood acute lymphoblastic leukemia. Int $J$ Cancer 2011;128:1632-43. DOI PubMed PMC

167. Von Behren J, Spector LG, Mueller BA, et al. Birth order and risk of childhood cancer: a pooled analysis from five US States. Int J Cancer 2011;128:2709-16. DOI PubMed PMC

168. Marcotte EL, Ritz B, Cockburn M, Yu F, Heck JE. Exposure to infections and risk of leukemia in young children. Cancer Epidemiol Biomarkers Prev 2014;23:1195-203. DOI PubMed PMC

169. Marcotte EL, Thomopoulos TP, Infante-rivard C, et al. Caesarean delivery and risk of childhood leukaemia: a pooled analysis from the Childhood Leukemia International Consortium (CLIC). Lancet Haematol 2016;3:e176-85. DOI PubMed PMC

170. Francis SS, Wallace AD, Wendt GA, et al. In utero cytomegalovirus infection and development of childhood acute lymphoblastic leukemia. Blood 2017;129:1680-4. DOI PubMed PMC

171. Francis SS, Selvin S, Metayer C, et al. Mode of delivery and risk of childhood leukemia. Cancer Epidemiol Biomarkers Prev 2014;23:876-81. DOI PubMed

172. Wang L, Gomez SL, Yasui Y. Racial and ethnic differences in socioeconomic position and risk of childhood acute lymphoblastic leukemia. Am J Epidemiol 2017;185:1263-71. DOI PubMed

173. Bona K, Blonquist TM, Neuberg DS, Silverman LB, Wolfe J. Impact of socioeconomic status on timing of relapse and overall survival for children treated on Dana-Farber Cancer Institute ALL Consortium Protocols (2000-2010). Pediatr Blood Cancer 2016;63:1012-8. DOI PubMed

174. Acharya S, Hsieh S, Shinohara ET, DeWees T, Frangoul H, Perkins SM. Effects of race/ethnicity and socioeconomic status on outcome in childhood acute lymphoblastic leukemia. J Pediatr Hematol Oncol 2016;38:350-4. DOI PubMed

175. Kehm RD, Spector LG, Poynter JN, Vock DM, Altekruse SF, Osypuk TL. Does socioeconomic status account for racial and ethnic disparities in childhood cancer survival? Cancer 2018;124:4090-7. DOI PubMed PMC

176. Bhatia S, Sather HN, Heerema NA, Trigg ME, Gaynon PS, Robison LL. Racial and ethnic differences in survival of children with acute lymphoblastic leukemia. Blood 2002;100:1957-64. DOI PubMed

177. Bhatia S, Landier W, Shangguan M, et al. Nonadherence to oral mercaptopurine and risk of relapse in Hispanic and non-Hispanic white children with acute lymphoblastic leukemia: a report from the children's oncology group. J Clin Oncol 2012;30:2094-101. DOI PubMed PMC

178. Rosenberg AR, Kroon L, Chen L, Li CI, Jones B. Insurance status and risk of cancer mortality among adolescents and young adults. Cancer 2015;121:1279-86. DOI PubMed PMC

179. Krakora R, Shih W, Popli P, et al. Impact of insurance status on survival outcomes in adults with acute lymphoblastic leukemia (ALL): a single-center experience. Clin Lymphoma Myeloma Leuk 2020;20:e890-6. DOI PubMed

180. Halpern MT, Ward EM, Pavluck AL, Schrag NM, Bian J, Chen AY. Association of insurance status and ethnicity with cancer stage at diagnosis for 12 cancer sites: a retrospective analysis. Lancet Oncol 2008;9:222-31. DOI PubMed

181. Butow P, Palmer S, Pai A, Goodenough B, Luckett T, King M. Review of adherence-related issues in adolescents and young adults with cancer. J Clin Oncol 2010;28:4800-9. DOI PubMed

182. Schmiegelow K, Heyman M, Gustafsson G, et al; Nordic Society of Paediatric Haematology and Oncology (NOPHO). The degree of myelosuppression during maintenance therapy of adolescents with B-lineage intermediate risk acute lymphoblastic leukemia predicts risk of relapse. Leukemia 2010;24:715-20. DOI PubMed

183. Landier W, Hughes CB, Calvillo ER, et al. A grounded theory of the process of adherence to oral chemotherapy in Hispanic and caucasian children and adolescents with acute lymphoblastic leukemia. J Pediatr Oncol Nurs 2011;28:203-23. DOI PubMed PMC

184. Koren G, Ferrazini G, Sulh H, et al. Systemic exposure to mercaptopurine as a prognostic factor in acute lymphocytic leukemia in children. N Engl J Med 1990;323:17-21. DOI PubMed

185. Bhatia S, Landier W, Hageman L, et al. 6MP adherence in a multiracial cohort of children with acute lymphoblastic leukemia: a Children's Oncology Group study. Blood 2014;124:2345-53. DOI PubMed PMC

186. Wu YP, Stenehjem DD, Linder LA, et al. Adherence to oral medications during maintenance therapy among children and adolescents with acute lymphoblastic leukemia: a medication refill analysis. J Pediatr Oncol Nurs 2018;35:86-93. DOI PubMed PMC

187. Rytting ME, Jabbour EJ, O'Brien SM, Kantarjian HM. Acute lymphoblastic leukemia in adolescents and young adults. Cancer 
2017;123:2398-403. DOI PubMed

188. Sharib J, Horvai A, Gray Hazard FK, et al. Comparison of Latino and non-Latino patients with Ewing sarcoma. Pediatr Blood Cancer 2014;61:233-7. DOI PubMed PMC

189. Pui CH, Sandlund JT, Pei D, et al. Results of therapy for acute lymphoblastic leukemia in black and white children. JAMA 2003;290:2001-7. DOI PubMed

190. Bleyer A, Tai E, Siegel S. Role of clinical trials in survival progress of American adolescents and young adults with cancer-and lack thereof. Pediatr Blood Cancer 2018;65:e27074. DOI PubMed PMC

191. Pulte D, Gondos A, Brenner H. Improvement in survival in younger patients with acute lymphoblastic leukemia from the 1980 s to the early 21st century. Blood 2009;113:1408-11. DOI PubMed

192. Talarico L, Chen G, Pazdur R. Enrollment of elderly patients in clinical trials for cancer drug registration: a 7-year experience by the US Food and Drug Administration. J Clin Oncol 2004;22:4626-31. DOI PubMed

193. Parsons HM, Penn DC, Li Q, et al. Increased clinical trial enrollment among adolescent and young adult cancer patients between 2006 and 2012-2013 in the United States. Pediatr Blood Cancer 2019;66:e27426. DOI PubMed PMC

194. Hamel LM, Penner LA, Albrecht TL, Heath E, Gwede CK, Eggly S. Barriers to clinical trial enrollment in racial and ethnic minority patients with cancer. Cancer Control 2016;23:327-37. DOI PubMed PMC

195. Tasian SK, Loh ML, Hunger SP. Philadelphia chromosome-like acute lymphoblastic leukemia. Blood 2017;130:2064-72. DOI PubMed PMC 